\title{
Advanced Fuels Campaign Execution Plan
}

Kemal Pasamehmetoglu

October 2010

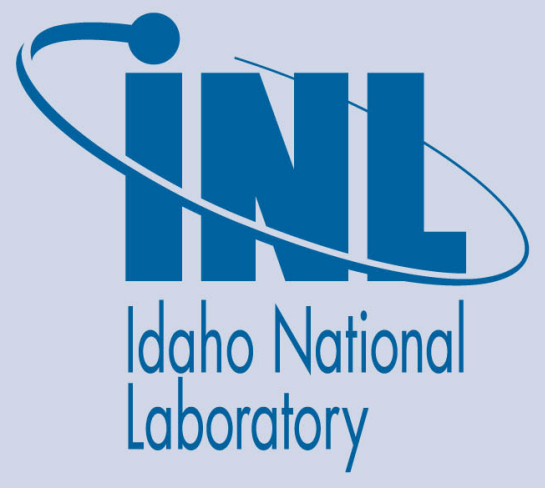

The INL is a U.S. Department of Energy National Laboratory operated by Battelle Energy Alliance 
INL/EXT-10-18954

FCRD-FUEL-2010-000058

\title{
Advanced Fuels Campaign Execution Plan
}

\author{
Kemal Pasamehmetoglu
}

October 2010

\author{
Idaho National Laboratory \\ Fuel Cycle Research \& Development \\ Advanced Fuels Campaign \\ Idaho Falls, Idaho 83415 \\ http://www.inl.qov
}

Prepared for the

U.S. Department of Energy

Office of Nuclear Energy

Under DOE Idaho Operations Office

Contract DE-AC07-05ID14517 


\section{DISCLAIMER}

This information was prepared as an account of work sponsored by an agency of the U.S. Government. Neither the U.S. Government nor any agency thereof, nor any of their employees, makes any warranty, expressed or implied, or assumes any legal liability or responsibility for the accuracy, completeness, or usefulness, of any information, apparatus, product, or process disclosed, or represents that its use would not infringe privately owned rights. References herein to any specific commercial product, process, or service by trade name, trade mark, manufacturer, or otherwise, does not necessarily constitute or imply its endorsement, recommendation, or favoring by the U.S. Government or any agency thereof. The views and opinions of authors expressed herein do not necessarily state or reflect those of the U.S. Government or any agency thereof. 
Submitted by:

Campaign Coordinator

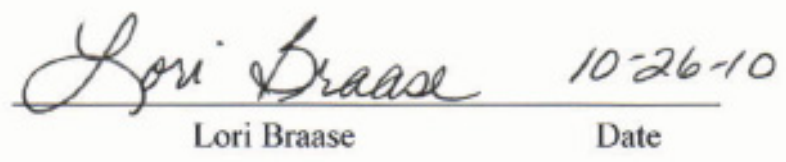

Approved by:

National Technical Director

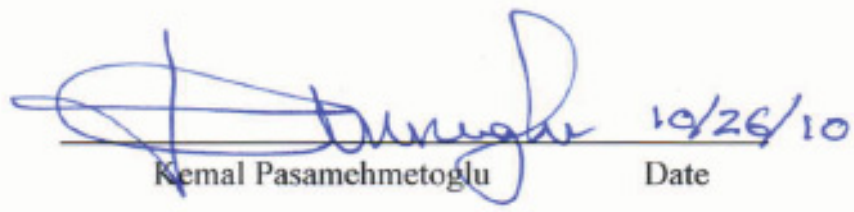

Approved by:

Federal R\&D Manager

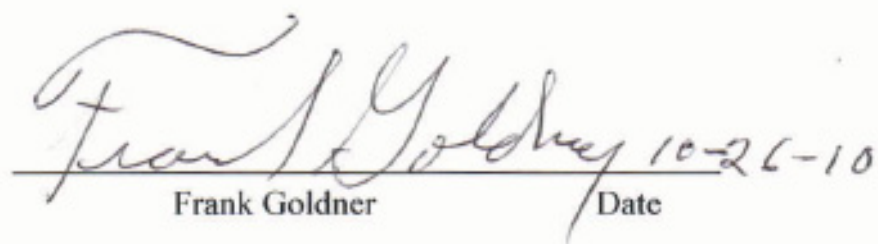


This page intentionally left blank. 


\section{EXECUTIVE SUMMARY}

The Advanced Fuels Campaign (AFC) Execution Plan communicates the structure and management of research, development, and demonstration (RD\&D) activities within the Fuel Cycle Research and Development (FCRD) program. The program has been given responsibility to develop advanced fuel technologies for the Department of Energy (DOE) using a science-based approach focusing on developing a microstructural understanding of nuclear fuels and materials. The science-based approach will combine theory, experiments, and multi-scale modeling and simulation aimed at a fundamental understanding of the fuel fabrication processes and fuel and clad performance under irradiation. The objective is to use a predictive approach to design fuels and cladding to achieve the desired performance (in contrast to more empirical observation-based approaches traditionally used in fuel development).

The scope of the AFC includes evaluation and development of multiple fuel forms to support the three fuel cycle options described in the Sustainable Fuel Cycle Implementation Plan ${ }^{4}$ : Once-Through Cycle, Modified-Open Cycle, and Continuous Recycle. The word "fuel" is used generically to include fuels, targets, and their associated cladding materials.

In the early phases of the program, the major fuel fabrication activities include development of innovative processes to enhance process efficiency and to improve the control of fuel microstructure for enhanced performance. Combined with advanced modeling and simulation, the focus is to predict and control fresh fuel properties given the feedstock characteristics and process parameters. The performance related activities include small-scale in-pile and out-of-pile phenomenological testing (in contrast with integral prototypic testing) and extensive characterization (with focus at micron-scale microstructural characterization of fuel and cladding) before and after testing. Larger-scale, prototypic experiments will be conducted in the later phases of the program only after a fundamental understanding of the fuel behavior is established and performance characteristics can be predicted. Then, fuels will be designed to specific performance requirements, thereby avoiding the need to perform large-scale experiments within a wide parametric range.

This document includes an overview of the FCRD program, a description of the difference between revolutionary and evolutionary approaches to nuclear fuel development, the meaning of science-based development of nuclear fuels, and the "Grand Challenge" for the AFC that would, if achieved, provide a transformational technology to the nuclear industry in the form of a high performance, high reliability nuclear fuel system. The AFC management structure, the activities that will be conducted by the AFC to achieve success towards the grand challenge, and the goals and milestones that will be achieved over the next 20 to 40 year period of research and development are also included.

The detailed milestones in the execution plan focus on the next 5 years (2011 through 2015) and are based on an assumed budget. It is expected that this execution plan will be revised on a yearly basis and the milestones recalibrated to actual budgets when the budget guidance is available. The overall objective for the first 5 years is a complete transition to a science-based fuel development paradigm while maintaining steady progress in a selected evolutionary path. 
This page intentionally left blank. 


\section{CONTENTS}

EXECUTIVE SUMMARY

ACRONYMS

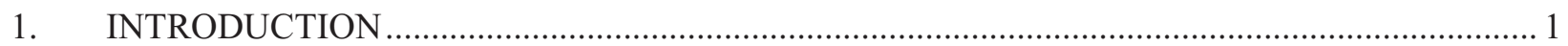

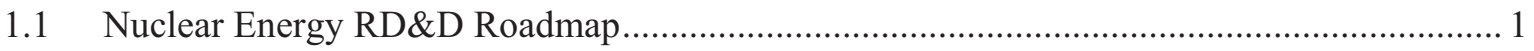

1.2 Sustainable Nuclear Fuel Cycle Implementation Plans .......................................................... 2

2. ADVANCED FUELS CAMPAIGN MISSION, SCOPE, AND OBJECTIVES ............................ 4

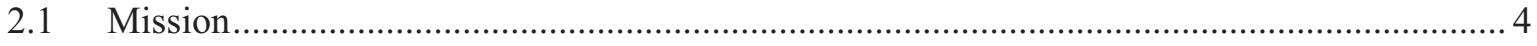

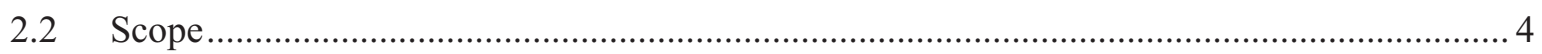

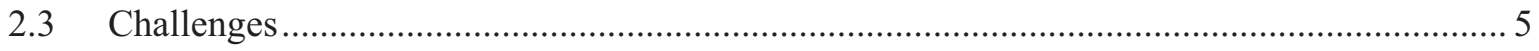

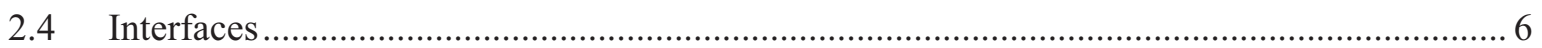

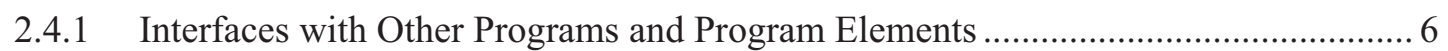

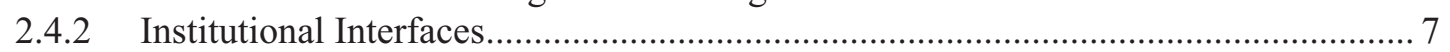

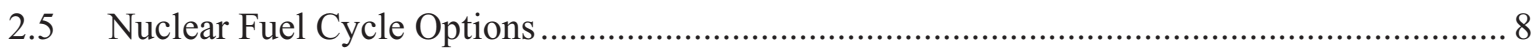

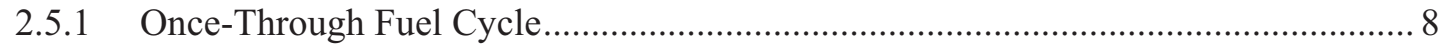

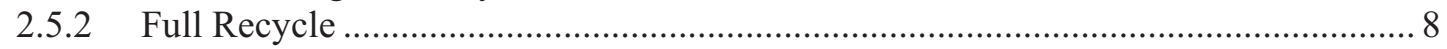

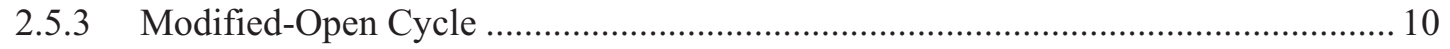

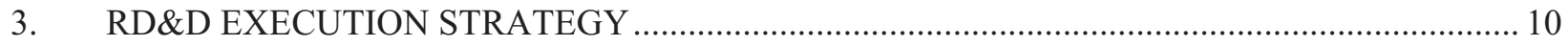

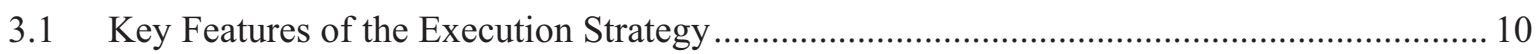

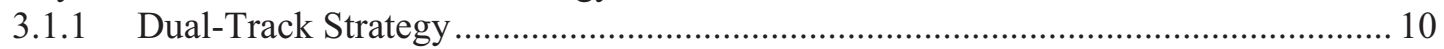

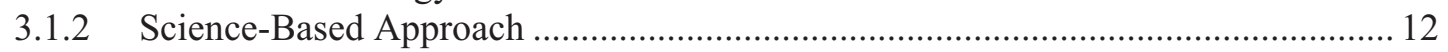

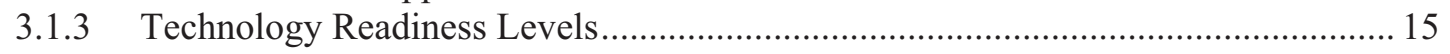

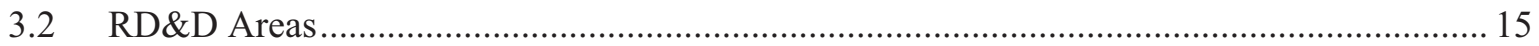

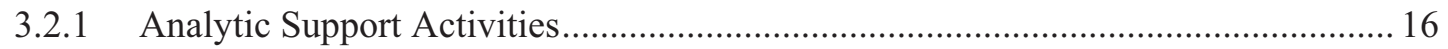

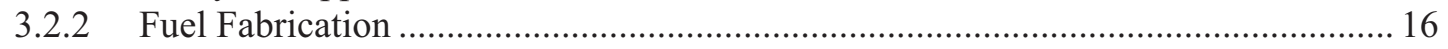

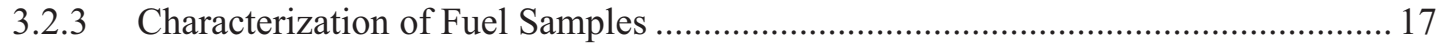

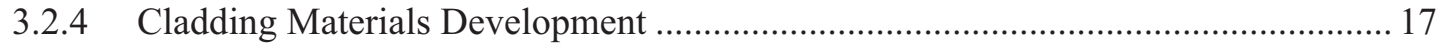

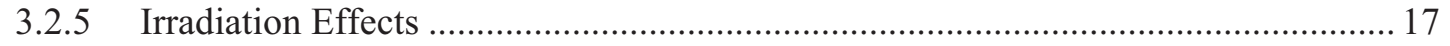

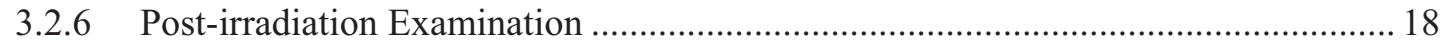

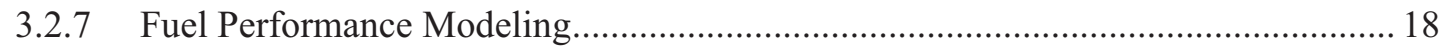

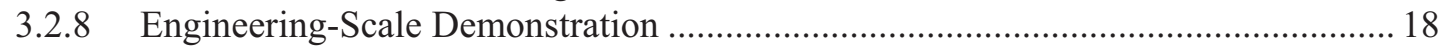

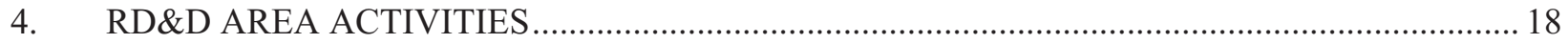

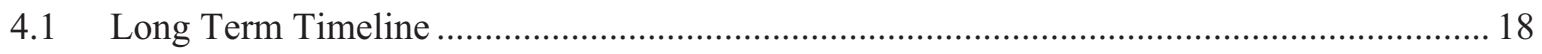

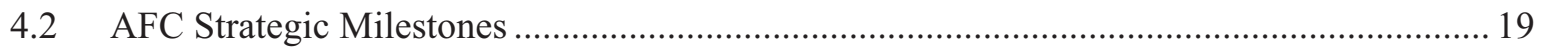

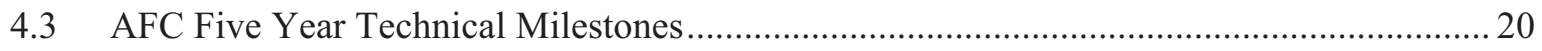

4.3.1 Analytic Support Five-Year Scope and Milestones ........................................... 21

4.3.2 Fuel Performance Modeling Five-Year Scope and Milestones ................................2 21

4.3.3 Metal Based Fuels Technologies Five-Year Scope and Milestones .......................... 21

4.3.4 Ceramic Based Fuels Technologies Five-Year Scope and Milestones ...................... 25

4.3.5 Coated Particle Fuels Technologies Five-Year Scope and Milestones .......................28

4.3.6 Core Materials Technologies Five-Year Scope and Milestones ................................ 30

4.3.7 Irradiation and Testing Five-Year Scope and Milestones ......................................... 32 


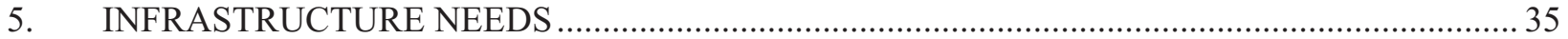

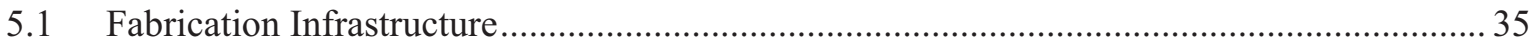

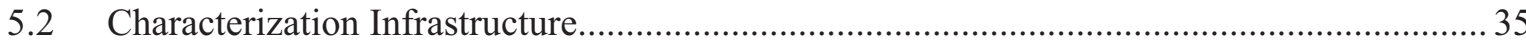

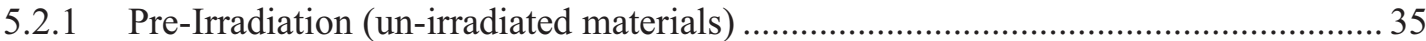

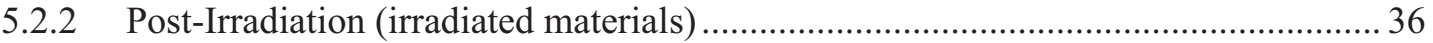

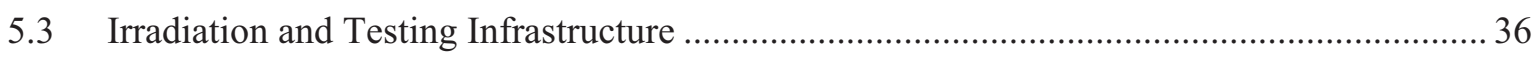

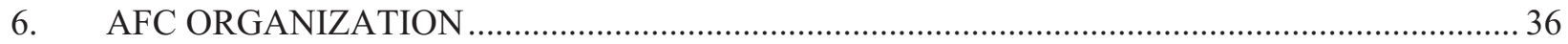

6.1 Advanced Fuels National Technical Director .................................................................. 37

6.2 Advanced Fuels Deputy National Technical Director ........................................................ 38

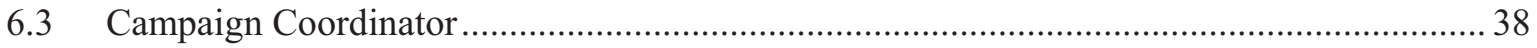

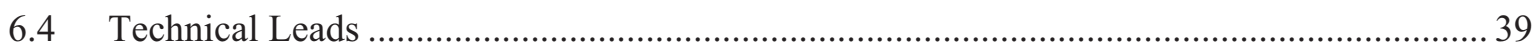

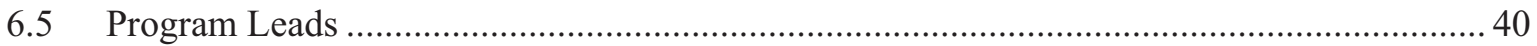

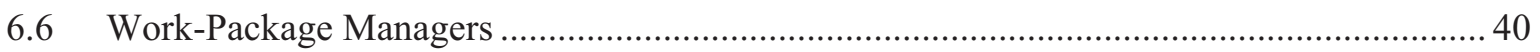

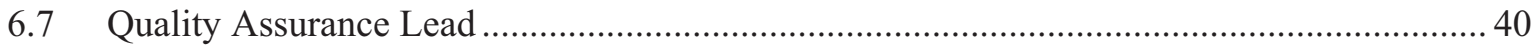

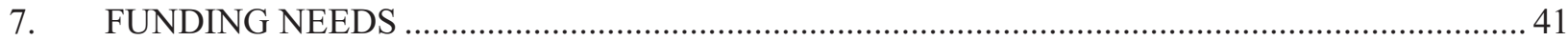

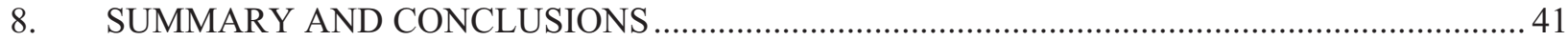

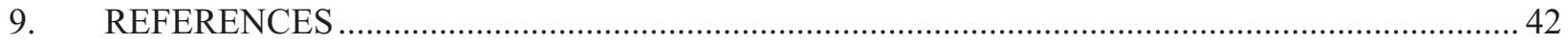




\section{FIGURES}

Figure 1. Four Objectives for Nuclear Energy RD\&D ......................................................................... 1

Figure 2. Fuel Cycle Options Considered Under Objective 3 ............................................................... 3

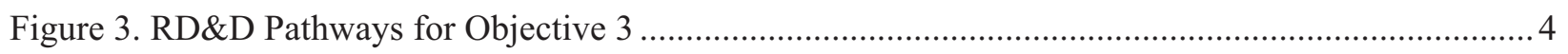

Figure 4. “Typical” Minimum Fuel Qualification Time Using a Heavily Empirical Approach..................6

Figure 5. High Level Schedule Constraints for Advanced Fuels Demonstration .................................... 9

Figure 6. Dual Track Strategy Using Evolutionary and Revolutionary Approaches Simultaneously ......... 11

Figure 7. Elements of the "Goal-Oriented Science-Based Approach" ................................................... 13

Figure 8. Science-Based Approach versus the Prototype Based Engineering Approach ......................... 14

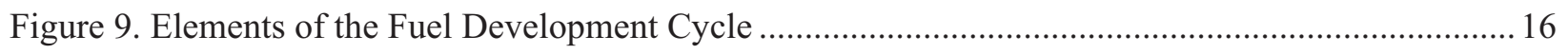

Figure 10. Metal Based Fuels Technologies 5-Year Milestones .............................................................2 24

Figure 11. Ceramic Based Fuels Technologies 5-Year Scope and Milestones.........................................2 27

Figure 12. Coated Particle Fuels Technologies 5-Year Scope and Milestones ........................................29

Figure 13. Core Materials Technologies 5-Year Scope and Milestones ................................................ 31

Figure 14. Irradiation and Testing 5-Year Scope and Milestones ....................................................... 34

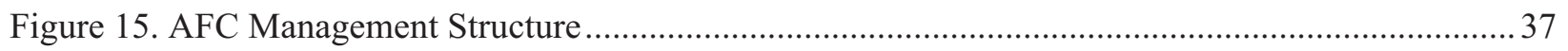

\section{TABLES}

Table 1. Criteria used for the Fuel Development TRL Definitions 


\section{ACRONYMS}

\begin{tabular}{|c|c|}
\hline $\mathrm{AFC}$ & Advanced Fuels Campaign \\
\hline AFCI & Advanced Fuel Cycle Initiative (Replaced by FCRD) \\
\hline ATR & Advanced Test Reactor \\
\hline ATR-NSUF & ATR National Scientific User Facility \\
\hline CEA & Atomic Energy Commission of France \\
\hline CRIEPI & Central Research Institute of Electric Power Industry \\
\hline $\mathrm{DB}$ & Deep Burn \\
\hline DOD & Department of Defense \\
\hline DOE & Department of Energy \\
\hline EPMA & Electron Probe Micro-Analyzer \\
\hline EPRI & Electric Power Research Institute \\
\hline FCCI & Fuel Cladding Chemical Interaction \\
\hline FCRD & Fuel Cycle Research and Development \\
\hline FFTF & Fast Flux Test Reactor \\
\hline FIB & Focused Ion Beam \\
\hline FR & Fast Reactor \\
\hline HFIR & High-Flux Isotope Reactor \\
\hline IMCL & Irradiated Materials Characterization Lab \\
\hline INL & Idaho National Lab \\
\hline ITU & Institute Of Transuranium Elements In Karlsruhe, Germany \\
\hline JAEA & Japan Atomic Energy Agency \\
\hline KAERI & Korea Atomic Energy Research Institute \\
\hline KMC & Kinetic Monte Carlo \\
\hline LANL & Los Alamos National Lab \\
\hline LEAP & Local Electrode Atom Probe \\
\hline LEU & Low Enriched Uranium \\
\hline LOCA & Loss of Coolant Accident \\
\hline LRUS & Laser Resonant Ultrasound Spectroscopy \\
\hline LTA & Lead Test Assembly \\
\hline LWR & Light Water Reactor \\
\hline LWRS & Light Water Reactor Sustainability \\
\hline MA & Minor Actinides \\
\hline MOTA & Materials Open Test Assembly \\
\hline MOX & Mixed Oxide \\
\hline $\mathrm{NE}$ & Nuclear Energy \\
\hline NEAMS & Nuclear Energy Advance Modeling and Simulation \\
\hline NEUP & Nuclear Energy University Program \\
\hline NGNP & Next Generation Nuclear Plant \\
\hline NRC & Nuclear Regulatory Commission \\
\hline PIE & Post Irradiation Testing \\
\hline RD\&D & Research, Development, and Deployment \\
\hline RERTR & Reduced Enrichment Research and Test Reactors \\
\hline SIMS & Secondary Ion Mass Spectrometry \\
\hline SMR & Small Modular Reactors \\
\hline TEM & Transmission Electron Microscope \\
\hline TRL & Technology Readiness Level \\
\hline TRU & Transuranic \\
\hline$\mu-\mathrm{XRD}$ & Micro x-Ray Diffraction \\
\hline
\end{tabular}




\section{ADVANCED FUELS CAMPAIGN EXECUTION PLAN}

\section{INTRODUCTION}

The Advanced Fuels Campaign (AFC) Execution Plan provides a summary level description of how the Advanced Fuels Research, Development, and Demonstration (RD\&D) pathway of the Fuel Cycle Research and Development (FCRD) program supports achievement of the overarching Department of Energy (DOE)-Nuclear Energy (NE) mission and program objectives. This execution plan is guided by the Nuclear Energy Research and Development Roadmap ${ }^{1}$ and the implementation plans for the research and development (R\&D) Objectives ${ }^{2,3,4,5}$ defined within the roadmap. The AFC Execution Plan will be maintained as a living document and updated on a yearly-basis.

\section{$1.1 \quad$ Nuclear Energy RD\&D Roadmap}

To achieve energy security and greenhouse gas emission reduction objectives, the United States must develop and deploy clean, affordable, domestic energy sources as quickly as possible. Nuclear power will continue to be a key component of a portfolio of technologies that meets our energy goals. DOE-NE recently developed a roadmap of its RD\&D activities that will ensure nuclear energy remains a compelling and viable energy option for the United States. ${ }^{1}$

DOE-NE organized the RD\&D activities according to four R\&D objectives that address the challenges of expanding the use of nuclear power (see Figure 1). The objectives are:

1. Develop technologies and other solutions that can improve the reliability, sustain the safety, and extend the life of current reactors

2. Develop improvements in the affordability of the new reactors to enable nuclear energy to help meet the Administration's energy security and climate change goals

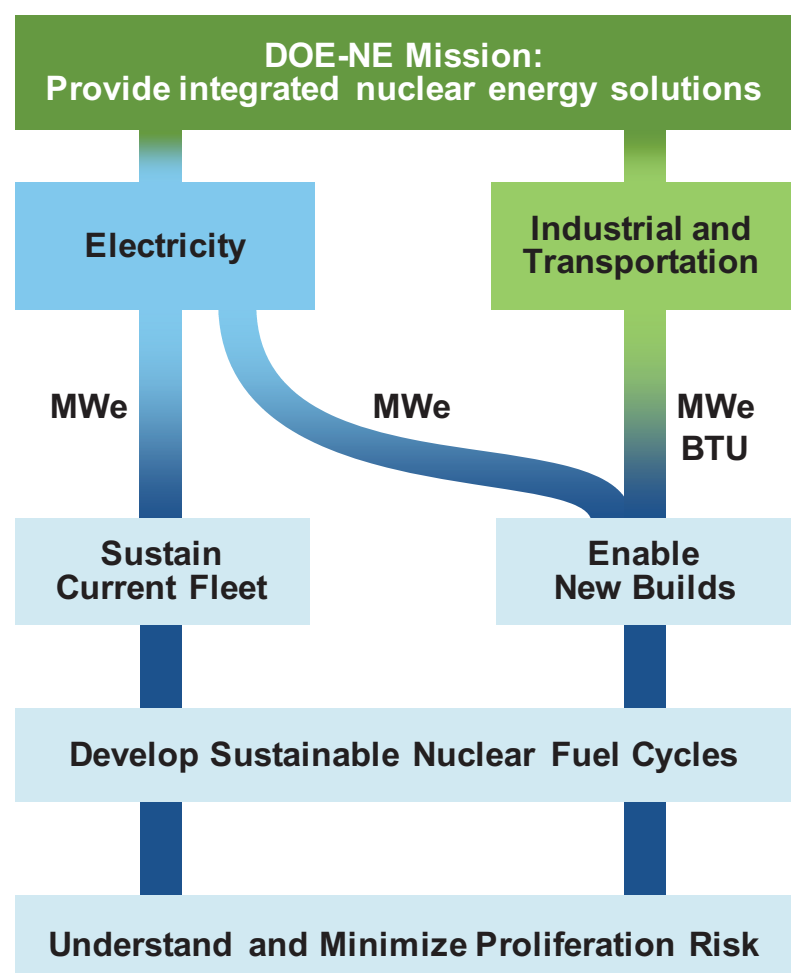

Figure 1. Four Objectives for Nuclear Energy RD\&D

3. Develop sustainable nuclear fuel cycles

4. Understand and minimize the risks of nuclear proliferation and terrorism.

Advanced Fuel RD\&D cross-cuts all the R\&D objectives, as discussed below:

- Objective 1: Develop technologies and other solutions that can improve the reliability, sustain the safety, and extend the life of current reactors - Extending the life-time of the existing reactor fleet does not require the development of advanced fuels. However, increasing 
the efficiency of the existing fleet in the future will require advanced fuels that can sustain higher power densities and achieve higher burnups.

- Objective 2: Develop improvements in the affordability of the new reactors to enable nuclear energy to help meet the Administration's energy security and climate change goals - High-burnup, high performance fuels will be required to support the full economic benefit of next generation nuclear plants. These new fuels will maximize the use of natural resources and minimize nuclear waste. Also included in the RD\&D portfolio are special long-life fuels for the small-modular reactors (SMRs) that have less frequent refueling. Typically, high-temperature reactors are used to produce process heat; therefore, advanced fuels that can operate under higher temperatures will be needed. However, the fuel (an improved version of the classical TRISO fuel) being developed for the Next Generation Nuclear Plant (NGNP) is covered under the NGNP Project Plan and is not part of this execution plan.

- Objective 3: Develop sustainable nuclear fuel cycles - A variety of advanced fuels is being considered in support of the different fuel cycle options. This will be covered in more detail in Section 1.2.

- Objective 4: Understand and minimize the risks of nuclear proliferation and terrorism Technologies that reduce the risk of proliferation may impact advanced fuel development, for instance: (a) the fuel composition may be affected by the type of separations or fuel treatment technologies used in various fuel cycles, (b) the fuel fabrication processes may be influenced by the safeguards considerations against diversion, or (c) materials accounting restrictions and implementation of advanced safeguards technologies may affect the fabrication process and plant designs.

\subsection{Sustainable Nuclear Fuel Cycle Implementation Plans}

Implementation plans are being developed for each of the R\&D objectives listed above. ${ }^{2,3,4,5}$ The Advanced Fuels Campaign is primarily focused on the RD\&D associated with Objective 3. Therefore, a high-level summary of the Sustainable Nuclear Fuel Cycle Implementation Plan ${ }^{4}$ is provided here.

Sustainable nuclear fuel cycle options are those that improve uranium resource availability and utilization, minimize waste generation, and provide adequate capability and capacity to manage all wastes produced by the nuclear fuel cycle. The key challenge for the government in this imperative is to develop a suite of options that will enable future decision-makers to make informed choices about how best to manage the used nuclear fuel from reactors. The overall goal is to demonstrate the technologies necessary to allow commercial deployment of solution(s) for the sustainable management of used nuclear fuel that is safe, economic, secure, and widely acceptable in American society before 2050.

Below are three potential fuel cycle strategies (see Figure 2) for used fuel management that together encompass all potential fuel cycle options.

- Once-Through Fuel Cycle - The goal of this strategy is to develop fuels for use in reactors that would increase the efficient use of uranium resources and reduce the amount of used fuel requiring direct disposal for each megawatt-hour $(\mathrm{MWh})$ of electricity produced. Once-through fuel cycle primarily applies to light water reactors (LWR).

- Modified Open Cycle - This strategy involves the investigation of fuel forms and reactors that would significantly increase fuel resource use and reduce the quantity of long-lived radiotoxic elements in the used fuel to be disposed (per MWh), with limited separations steps using technologies that substantially lower proliferation risk. Additionally, this strategy includes evaluating non-uranium materials (e.g., thorium) as reactor fuel options that may reduce the longlived radiotoxic elements in the used fuel that would go into a repository. 
- Full Recycle - This strategy is aimed at developing techniques that will enable the long-lived actinide elements to be repeatedly recycled rather than disposed. The ultimate goal is to develop a cost-effective and low proliferation risk approach that would dramatically decrease the longterm danger posed by the waste, reducing uncertainties associated with its disposal.

\section{Optimized Once-Through}

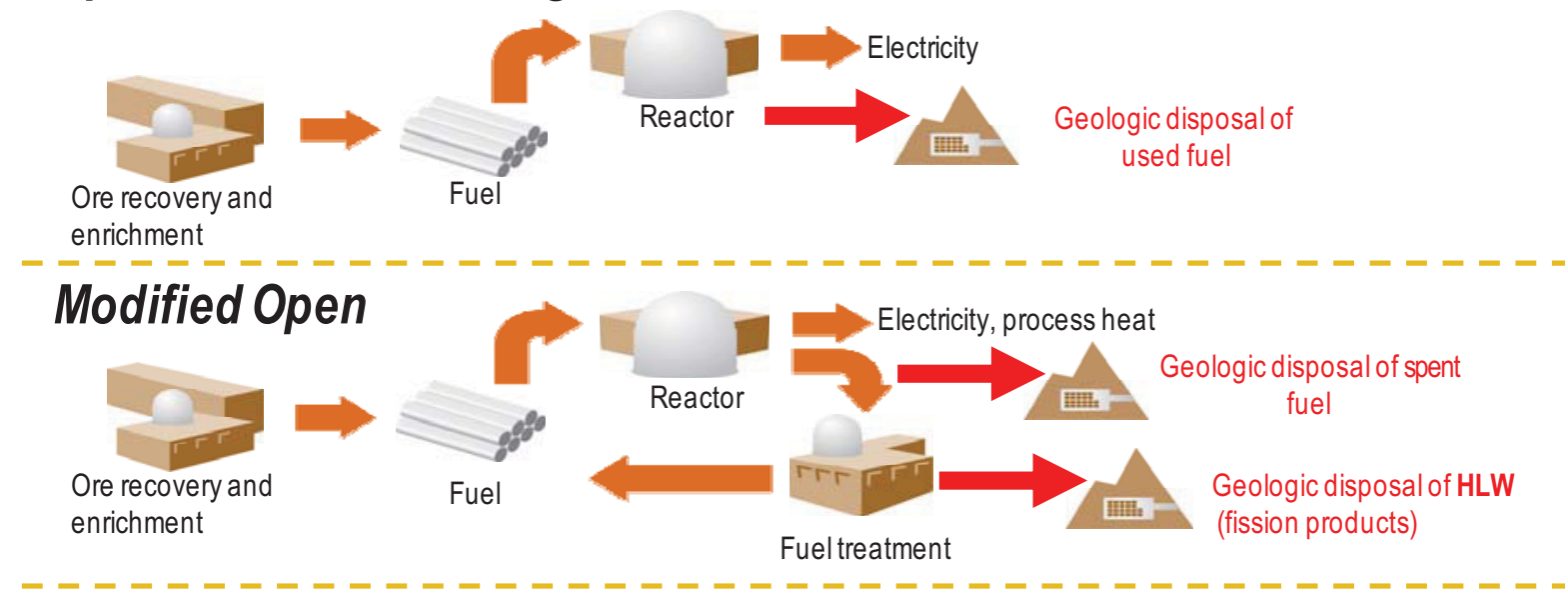

\section{Full Recycle}

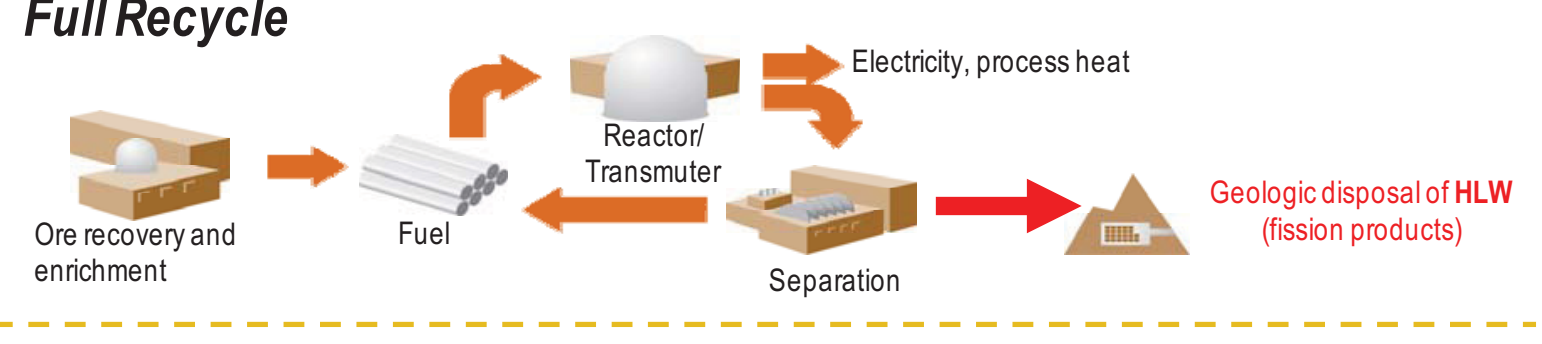

Figure 2. Fuel Cycle Options Considered Under Objective 3

The goal is to first develop innovative and preferably transformational options within each of these fuel cycle strategies and successively winnow the options leading to demonstration once the RD\&D is sufficiently advanced, perhaps twenty or thirty years from now. The implementation strategy relies on:

- A dual track approach for technology development with specific goals combining evolutionary and revolutionary tracks

- A science-based approach for innovation and pursuit of multiple options in early phase of the program, where small-scale experimentation, theory development, and modeling and simulation are combined to achieve a fundamental understanding of various technologies

- Integration through application of systems analysis tools applicable at different phases of the program. 
Understanding the options in each of the three fuel cycle strategies will require development of advanced technologies in eight critical technical areas (referred to as RD\&D pathways). Each of these could have enabling technologies that will also have to be developed. Most of these RD\&D pathways apply to all three fuel cycle strategies, but some pathways only apply to one or two of the strategies. For example, separations technologies clearly do not apply to the oncethrough fuel cycle. Additionally, specific technologies will be different for each potential option within each strategy. The research pathways shown in Figure 3 are as follows:

- Systems Analysis

- Fuel Resources

- Advanced Fuels Development

- Separations

- Waste Forms

- Storage and Disposal

- Transmutation Technologies (including advanced reactors)

- Materials Protection, Control, and Accountability Technologies.

\section{ADVANCED FUELS CAMPAIGN MISSION, SCOPE, AND OBJECTIVES}

As discussed in the previous section, development of advanced fuels cross-cuts all four objectives and the three broad fuel cycle categories under the Sustainable Nuclear Fuel Cycle R\&D Objective. In this section, a high-level definition of the mission, challenges, interfaces, and schedule constraints for the advanced fuels RD\&D pathway are presented.

\subsection{Mission}

The development of advanced fuels is an RD\&D pathway within the FCRD program. The mission of the Advanced Fuels Campaign is to conduct RD\&D to develop various novel fuel forms (including cladding) needed for the implementation of the different fuel cycle options defined in the Sustainable Nuclear Fuel Cycle Implementation Plan. ${ }^{4}$

\subsection{Scope}

The full-scope of the Advanced Fuels Campaign includes assessment of fabrication processes and performance of multiple fuel types and materials:

- Advanced cladding and core materials in contact with various coolant types used in the reactors and transmuters (both thermal and fast spectrum systems) 
- Metallic, ceramic, and composite (dispersion in the form of CERCER and CERMET) fuels

- Pelletized, powder-loaded (Vibropac), sphere-pac, and particle fuel

- Fuels containing fissile and fertile materials

- Targets used for heterogeneous transmutation of minor actinides (MAs)

- Fuel types that can be used both in thermal- and fast-spectrum systems

- Fuels that contain uranium and all or some of the transuranic (TRU) elements

- Fertile free fuels and targets that contain no uranium

- Fuels that contain fertile thorium

- Fuels and targets considered under modified open cycle that initially contain considerable impurities (e.g., fission products).

Assessment of fabrication processes and performance of these fuels and materials will require that the following be included in the overall scope:

a. Development and validation of multi-scale analysis tools that predict fabrication process outcomes and irradiation performance

b. Development of a process to screen fuel and cladding candidates, including identifying the screening criteria

c. Development of the information for each fuel and cladding candidate according to the screening criteria

d. Demonstration of acceptable fabrication and performance (both normal and off-normal) of selected fuels and claddings.

For any given fuel type, the mission of the Advanced Fuel Campaign ends when fuel qualification is completed via an engineering-scale demonstration of the fabrication processes and irradiation of lead-test assemblies (LTAs) to demonstrate the in-pile performance.

\subsection{Challenges}

It takes approximately 20 years and substantial funding to qualify a new fuel type for any system. A typical, empirically-dominated, engineering-scale fuel qualification cycle is shown in Figure 4. Typically engineering-scale model development activities are also involved, but are not shown in the figure. At the end of the cycle, the operating envelope of the fuel when deployed is determined conservatively by the observations made during the various stages of testing. The final operating envelope may or may not meet all the design objectives set forth in the earlier conceptual stage. The objectives for fabrication processes and in-pile performance, for the advanced fuels considered, are aggressive. Implementing a similar cycle to a multitude of fuel forms and types considered under the Advanced Fuels Campaign would be very difficult (if feasible) given the cost, schedule, and resource constraints. Thus, a new development paradigm is needed where the options can be narrowed down with high confidence at the early stages of the research and, for the selected options the amount of iterative testing is reduced via predictive tools. This is the basis for the "goal-oriented science-based approach" to fuel development that is discussed in Section 3. 


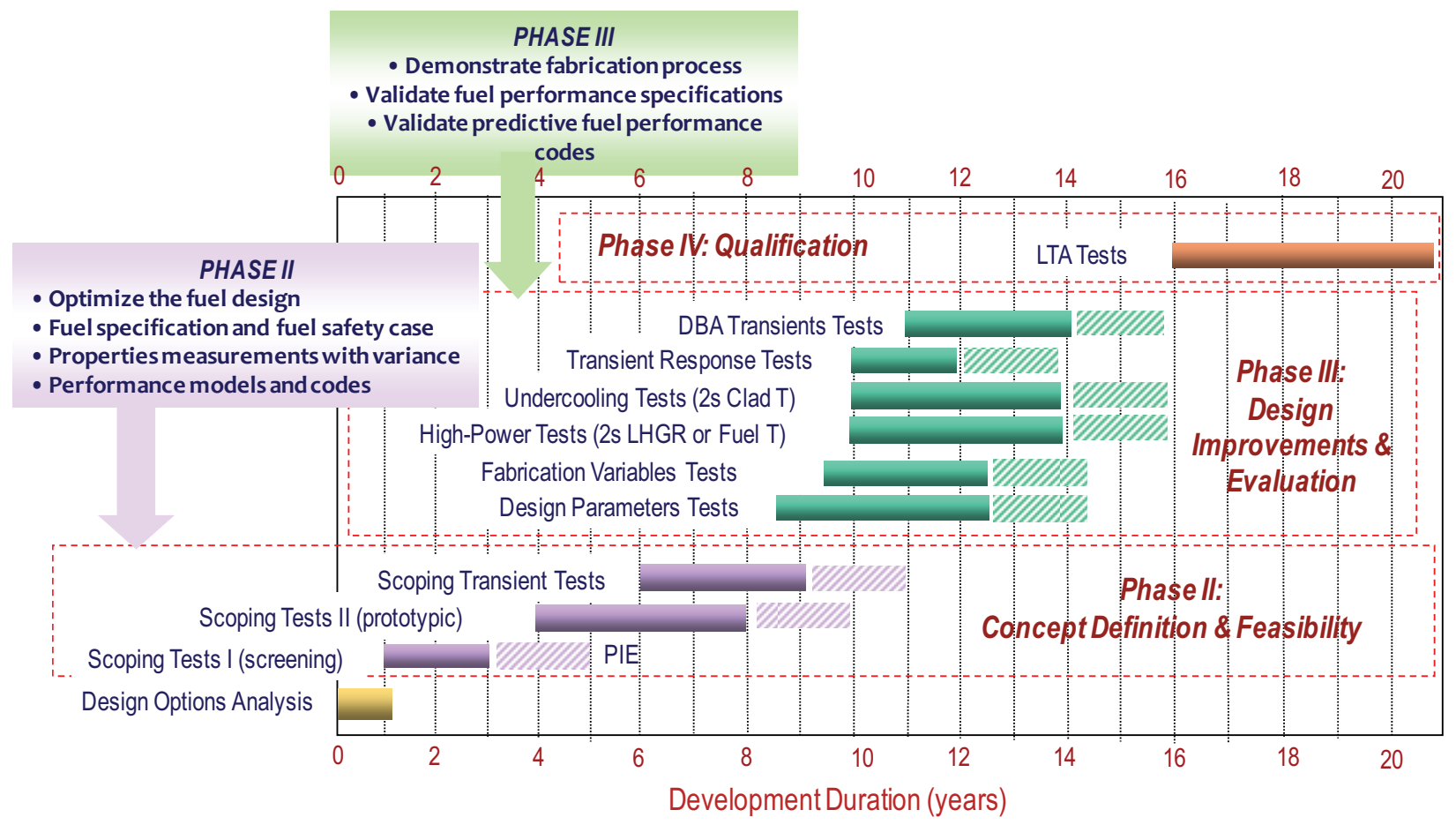

Figure 4. "Typical” Minimum Fuel Qualification Time Using a Heavily Engineering-scale Empirical Approach

\subsection{Interfaces}

Advanced fuel development cannot be implemented in isolation from the other DOE RD\&D programs. Likewise, the successful development strategy requires interfacing with national and international institutions outside DOE.

\subsubsection{Interfaces with Other Programs and Program Elements}

The Advanced Fuels Campaign under R\&D Objective 3 (Sustainable Nuclear Fuel Cycles) interfaces with all the other R\&D Objectives within the $N E R \& D$ Roadmap ${ }^{1}$ and with all the RD\&D pathways defined in the Sustainable Nuclear Fuel Cycle Implementation Plan. ${ }^{4}$

- Nuclear Energy Advanced Modeling \& Simulation (NEAMS) - Advanced modeling and simulation is managed and executed as a crosscutting program within DOE-NE. Advanced fuels $M \& S$ activities are included within NEAMS. However, such activities must be closely coordinated with the theory development and experimental activities contained in the Advanced Fuels Campaign. A strong interface with NEAMS and close coordination of the activities is essential in using M\&S as a strong element of the science-based fuel development strategy.

- Reactors/Transmuters - The strongest technical interface for the Advanced Fuels Campaign is the Reactor and Transmuter Technology Teams. Any fuel form/type being developed to increase the efficiency of the existing LWR fuels must be compliant with the operation and safety envelopes of the existing reactors. For new reactor designs, strong collaboration is needed between the system designers and the fuel designers to achieve the desired operation and safety envelopes. Qualification of advanced fuels will require irradiation of lead test assemblies (LTAs, described later), which will require the existence of a suitable transmuter facility, e.g., demonstration fast reactor. 
- Separations/Fuel Treatment - Another strong technical interface is with the Separations and Fuel Treatment Teams. The feedstock for the fabrication of some advanced fuel forms (those used in modified open or full recycle fuel cycle options) will be provided by the separations/fuel treatment facilities. Thus, the feedstock must meet the requirements imposed by the fabrication processes. Some of the advanced fuels discharged from the reactors/transmuters will require additional separations/treatment and must be compliant with the separations or treatment processes.

- Storage and Disposal - Every new fuel type being developed must be compliant with the storage requirements at discharge. For certain scenarios, the fuel may be disposed as discharged without additional treatment; in this case disposal requirements become important for the end-of-life conditions of the advanced fuels.

- Safeguards - The fabrication processes and eventual fabrication facilities must be compliant with the safeguards and materials accounting requirements, and must be able to accommodate the advanced technologies developed for these purposes. The Advanced Safeguards Development Team must be familiar with the proposed fabrication processes to properly implement the "safeguards by design" concepts.

- Waste Forms - Both high-level and low-level nuclear waste is generated during fabrication, treatment, and separations of the advanced fuel forms. Thus, the Waste Form Team must be able to convert the generated waste into a suitable form for disposal.

- Systems Analysis - Like all the RD\&D elements, advanced fuels development must be closely coordinated with the systems level analysis for the nuclear energy deployment and fuel cycle options. Advanced Fuels Campaign generates technology data to be used in systems analysis and Systems Analysis provides the necessary boundary conditions, constraints and requirements to guide the advanced fuel development.

\subsubsection{Institutional Interfaces}

The RD\&D activities for the development of advanced fuels are lead by the National Laboratories on behalf of DOE-NE. Therefore, strong collaborations among the National Laboratories and with other institutions outside the DOE complex are needed for a successful integration and execution.

- National Laboratories - DOE National Laboratory complex directs most of the advanced fuels RD\&D activities. This effort is lead by Idaho National Laboratory (INL), designated the NE Lead Laboratory. Much of the actual work can be performed at the INL complex. However, other national laboratories also contain indispensable expertise and research facilities needed for the successful execution of the program. Thus, the Advanced Fuels Campaign is formed though participation of multiple national laboratories in the leadership and execution roles.

- University Collaborations - Strong collaboration with universities is essential for advanced fuel development. The intellectual participation of the universities will supplement the much needed innovative thinking required for the implementation of a science-based approach to fuel development. Because of the limited research activities in the previous decade, the expertise supporting the fuel development activities is limited and aging. There is an immediate need to educate the next generation of fuels engineers and scientists to provide continuity for long-term RD\&D activities.

- Industry - RD\&D for advanced fuels is long-term, risky, and expensive. Therefore, industry on its own will not perform the desired research and will naturally focus on incremental improvements on today's technology. On the other hand, nuclear energy production is a private enterprise in the U.S. and any advanced fuels developed under this program, if successful, will be 
commercialized by the private sector. Thus, it is important to partner with industry at the early stages of the research to facilitate the eventual and timely commercialization process.

- International Collaborations - Because of the complicated nature of the fuel development and the need to explore multiple options in the early phases of the program, International collaborations with considerable nuclear energy infrastructure is essential. Currently, the Advanced Fuels Campaign has strong collaborative ties with France (CEA), Japan (JAEA, CRIEPI), European Union (ITU), China, and South Korea (KAERI). Future potential collaborations include Canada, United Kingdom, and Russia.

There will be specific milestones under different international collaboration agreements with emphasis on joint irradiation testing.

- Nuclear Regulatory Commission (NRC) - The NRC must license any new fuel developed by the Advanced Fuels Campaign before it can be deployed in commercial nuclear reactors. Therefore early involvement of NRC in the RD\&D phase will enable timely licensing of the eventual products. This is especially true if there is a change in the licensing paradigm as a result of a goal-oriented science-based approach to fuel development.

\subsection{Nuclear Fuel Cycle Options}

The Sustainable Nuclear Fuel Cycle Implementation Plan ${ }^{4}$ provides a high-level schedule for advanced fuels development. The overall goal is to have demonstrated the technologies necessary to allow commercial deployment of solution(s) for the sustainable management of used nuclear fuel that is safe, economic, and secure and widely acceptable to American society by 2050 . The implementation plan for R\&D Objective 1 includes a goal for demonstration of the high-burnup fuels for use in LWRs by $2035 .^{2}$ These goals are translated to advanced fuel development (refer to figure 5) as follows:

\subsubsection{Once-Through Fuel Cycle}

Assuming the once-through fuel cycle applies to the use of LWRs and does not require construction of large-scale fuel fabrication facilities or a new reactor, a qualification date of 2035 is achievable.

2035: Complete a successful irradiation and post-irradiation examination of lead test assemblies (LTAs) for high-burnup, high-performance LWR fuel.

This requires that the LTAs are inserted into a LWR no later than $\sim 2030$. A preliminary development schedule based on these constraints is presented in Sections 4 and 6

\subsubsection{Full Recycle}

The fuels for full recycle require remote fabrication. Thus, in addition to the development of technologies, the LTA testing for full-recycle option requires the availability of an assembly-scale remote fabrication facility and a prototype fast reactor. Because full recycle requires continuous recycling of the fuel, at least two cycles through the fast reactor may be needed for qualification (this depends on burnup in a single pass and the cost-benefit analysis of continuous recycling). The qualification date of 2050 is interpreted in the dates below. A preliminary development schedule based on these constraints is presented in Sections 4 and 6.

2050: The second-pass LTA testing is complete

2043: The first pass LTA testing is complete

2035: Assembly fabrication facility and prototype fast reactor are available. 


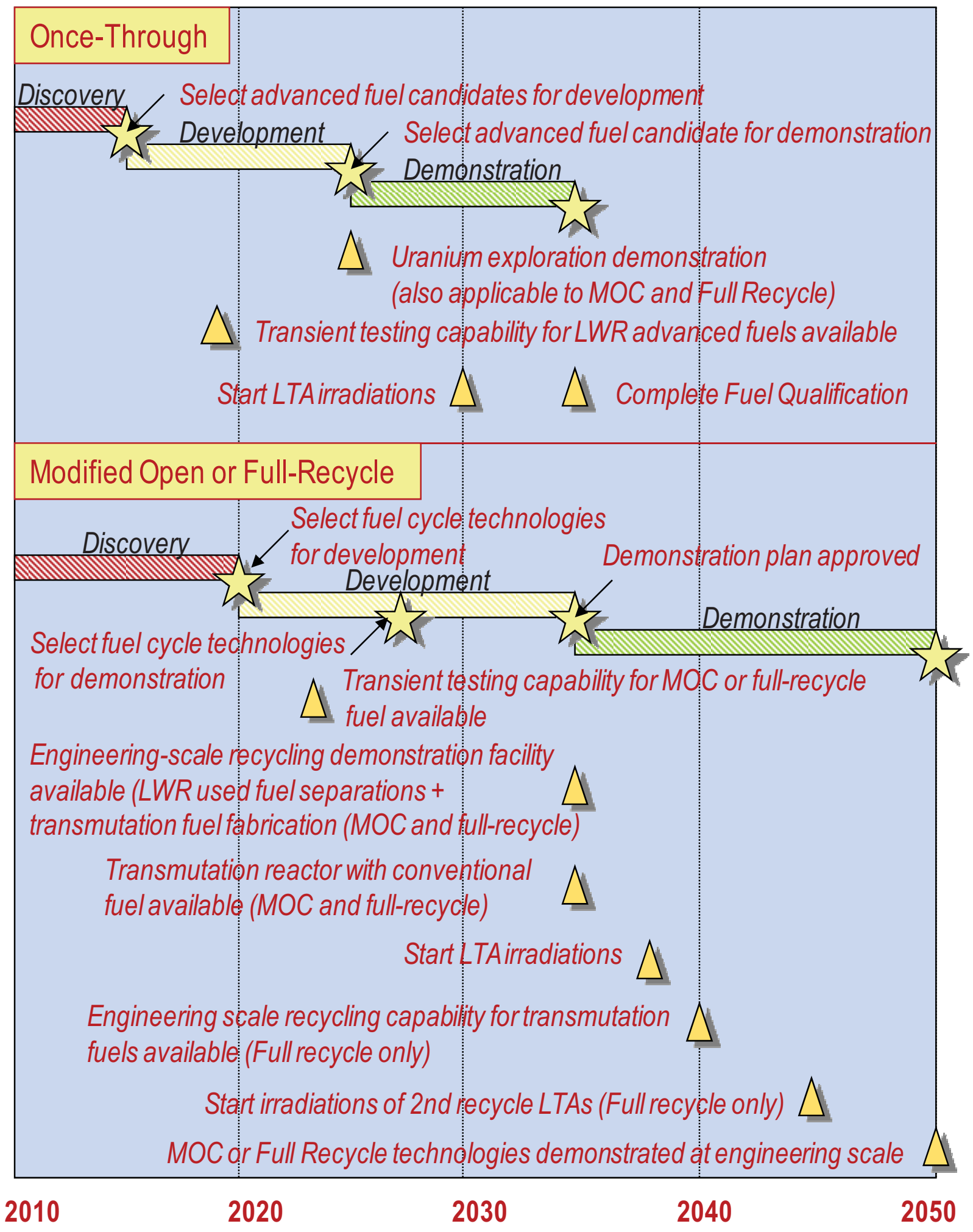

Figure 5. High Level Schedule Constraints for Advanced Fuels Demonstration 


\subsubsection{Modified-Open Cycle}

There are a number of options being considered for the modified open cycle, some of which may require remote fabrication. Depending upon the selection of the specific technologies and associated facilities for demonstration, the target dates may range between 2035 and 2050. If remote fuel fabrication, chemical separations, and a new reactor prototype are needed, the demonstration date will likely be the same as the full recycle option $(\sim 2050)$.

\section{RD\&D EXECUTION STRATEGY}

In this section, the key features of the implementation strategy are introduced; along with the break-down of the advanced fuel scope into key RD\&D elements.

\subsection{Key Features of the Execution Strategy}

The Execution strategy relies on the following key features:

- Dual-track strategy with grand-challenges

- Goal-oriented science-based approach

- Technology Readiness Level (TRL) definitions.

- Interfaces as discussed in Section 2.4.

\subsubsection{Dual-Track Strategy}

The dual-path approach of the Advanced Fuels Campaign requires that RD\&D serve two purposes. First, develop the fuels needed to define and demonstrate advanced reactor and fuel cycle options with sufficient certainty that program milestones and budgets can be reasonably anticipated and planned. This near-to-mid-term focus will be accomplished using evolutionary advances on current knowledge. To meet this objective, the program will systematically define and evaluate fuels along with associated technologies, to successively down-select the leading candidates for baseline technologies that will lead to future industrial-scale demonstration. The best technologies available at the time will be used for conceptual design of demonstration facilities.

Second, explore and discover new innovative, revolutionary fuels that can fundamentally improve our ability to meet program objectives. The program will also pursue long-term, high-risk, high-payoff RD\&D. This part of the program will seek revolutionary and transformational breakthroughs in areas of fuel and fabrication process design that can better meet the program objectives.

The dual-track parallel approach using evolutionary and revolutionary RD\&D paths is shown in Figure 6 . While evolutionary advancements are being made to provide a reference (for demonstration goals and technical evaluations), revolutionary advancements are simultaneously being pursued that if successful, could replace all or part of the reference technologies. The science-based approach allows and fosters this dichotomy. 


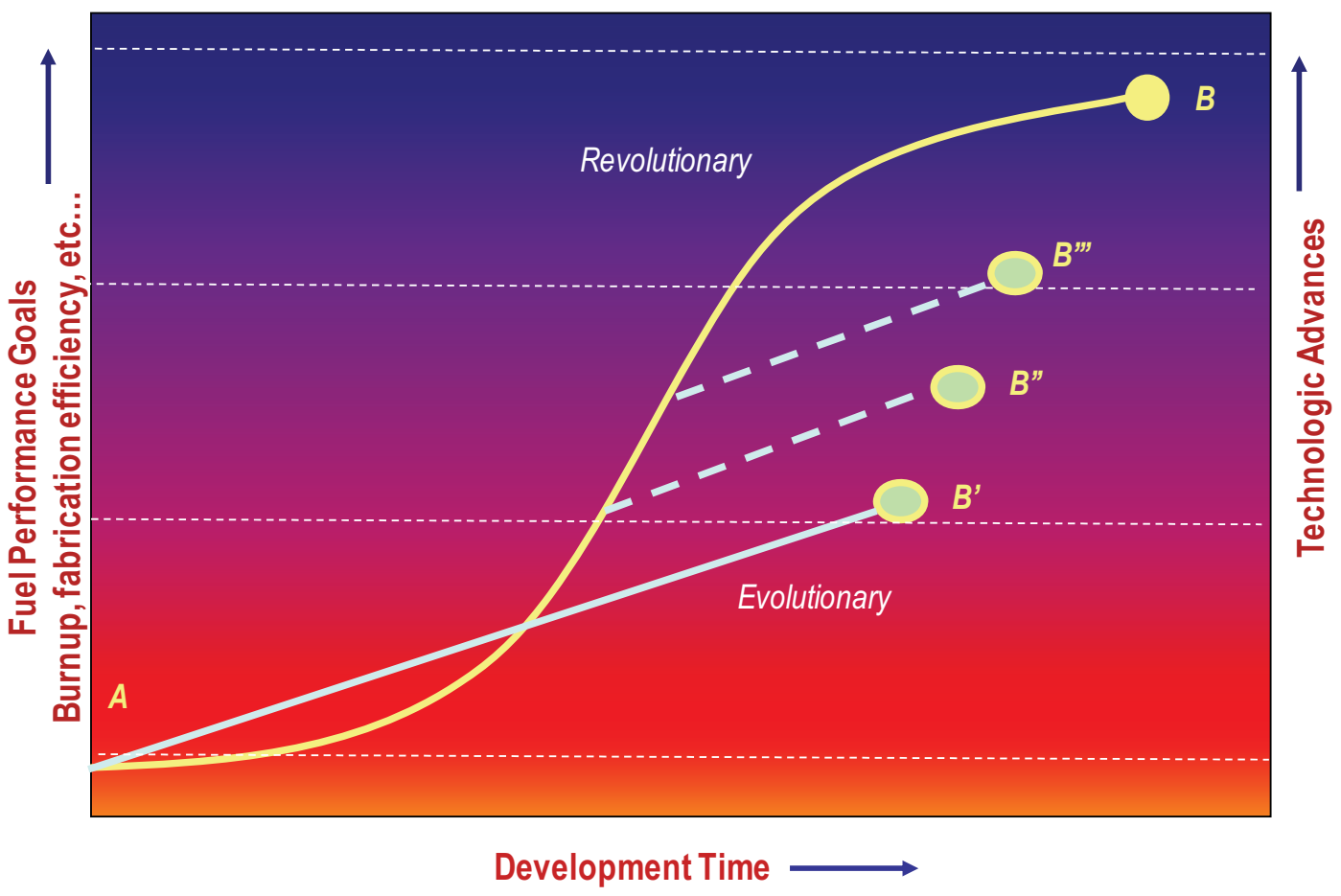

Figure 6. Dual Track Strategy Using Evolutionary and Revolutionary Approaches Simultaneously

As the program shifts to the science-based approach there will be an early incubation period of relatively slow progress, where new processes, tools, and capabilities are developed and deployed (see Figure 6). Once the tools are in place rapid progress will be made to improve the technologies for designing and fabricating high performance fuels and increasing the technical readiness of those fuel types. In addition, it is expected that the tools will trigger the generation of additional novel and transformational ideas. Therefore, to take full advantage of the benefits of the science-based approach and the tools being developed to support it, rush to an early down selection of technologies and strict technical requirements that would hinder innovation and transformational ideas must be avoided. When the period of rapid progress is achieved, periodic reviews will be conducted to evaluate whether new technologies should replace some or all of the evolutionary technologies being developed.

New ideas for revolutionary fuel cycle options and relevant technologies will be pursued via several avenues, including:

- Grand challenges established to develop advanced fuels

- Programmatic RD\&D focused on solving the grand challenges conducted primarily by national laboratories

- NE University Program (NEUP) process funded annually to solicit input from a wide array of U.S. universities

- Open competitions designed to foster collaborations with industry, national laboratories, and universities.

The dual track approach allows for flexibility in the technology choices in the near term and enables the program to adjust to the future needs and potential policy changes. The dual track approach also brings in the goal-oriented attribute to the proposed science-based approach. 


\subsubsection{Baseline Technologies for Evolutionary Approach}

The candidates for initial baseline are

- Uranium-based ceramic fuels with advanced zircalloy cladding for high burnup, high-power density LWR fuels to support the improved once-through fuel cycle option.

- Metallic fuels encased in HT-9 cladding for fast reactors in support of the modified open and continuous recycle options. Under the previous program, metal and oxide fuels were being developed for TRU bearing fast reactor advanced fuels. Because the development of the oxide fuels continue under the Japanese and French program for advanced applications, an evolutionary version of the metal fuel is selected as the baseline for the U.S. program. However, exploring a fundamental understanding of the oxide fuels remains within the FCRD program as part of the science-based approach leading to a revolutionary fuel form.

- Modified open cycles require innovative fuel concepts and no baselines are established. The performance of such fuels will be gauged against the LWR and Fast Reactor (FR) fuel baselines listed above.

\subsubsection{Advanced Fuels Grand Challenges}

For advanced fuels two categories of grand challenges are identified:

1. Major Increase in Fuel Burnup and Performance over the Current Technologies - For all the fuel cycle options, an increase in fuel burnup is desired. However, the quantitative goals for burnup depend on the reactor type and more importantly, the selected fuel cycle options. In some cases, there are practical and economic limitations to burnup beyond the fuel cycle efficiency and technology limitations. Clearly, burnup in once-through cycles is limited by the initial enrichment constraints and clad material properties. Burnup for fuels under the modified open cycle may be limited by reactor physics, storage, and disposal constraints after the discharge of spent fuel. Another important consideration in increasing the burnup is to ensure zero-failure, a standard that industry is striving for at current moderate burnups. Quantitative limits for the burnup grand-challenge under various fuel cycle scenarios will be developed as the program progresses and fuel cycle scenarios are defined.

2. Near Zero-loss Fuel Fabrication Processes - For fabrication, the challenge is to lower the irretrievable losses to near $0 \%$ from the current levels, which are typically on the order of $1 \%$. This requires the development of cleaner and more efficient fabrication processes without imposing an economic penalty on fuel fabrication. The objective is to generate less waste during the fabrication process and utilize the resources. Such improved fabrication processes also increases the safety of the plants and enhances the safeguards and materials accounting.

\subsubsection{Science-Based Approach}

Fuel development and qualification is a lengthy and expensive process. The traditional empirical approach to fuel development (sometimes unfairly referred to as the "cook and look") is not amenable to conducting research on multiple fuel forms and types with very aggressive performance objectives. In addition, resource limitations in the form of budgets, human resources, and facilities further complicate the situation. Fortunately, the advances made in fundamental understanding of materials, instrumentation and measurement techniques, and development and growth of high performance computing provide a means to overcome these barriers and implement a new approach to research and development. Termed the "science-based" approach, this process involves small-scale experiments, coupled with theory 
development and advanced modeling and simulation to reduce the number and cost of engineering-scale tests (see Figure 7).

- Experiments - As opposed to large-scale, integrated experiments typical of demonstration-based programs, the focus on the experiments for a science-based approach shifts to smaller-scale, phenomenological, fundamental mechanisms, and integral effects testing aimed at measurement of fundamental properties. This approach provides a fundamental understanding of targeted phenomena and the data needed for model development. New and innovative experimental design and novel measurement techniques will need to be incorporated into experimental programs to permit these types of experiments to be conducted. In some cases targeted integral experiments will also be needed. However, small-scale integral testing combined with scientifically developed scaling laws may alleviate the need of full-scale experiments. Novel measurement techniques with high spatial resolution

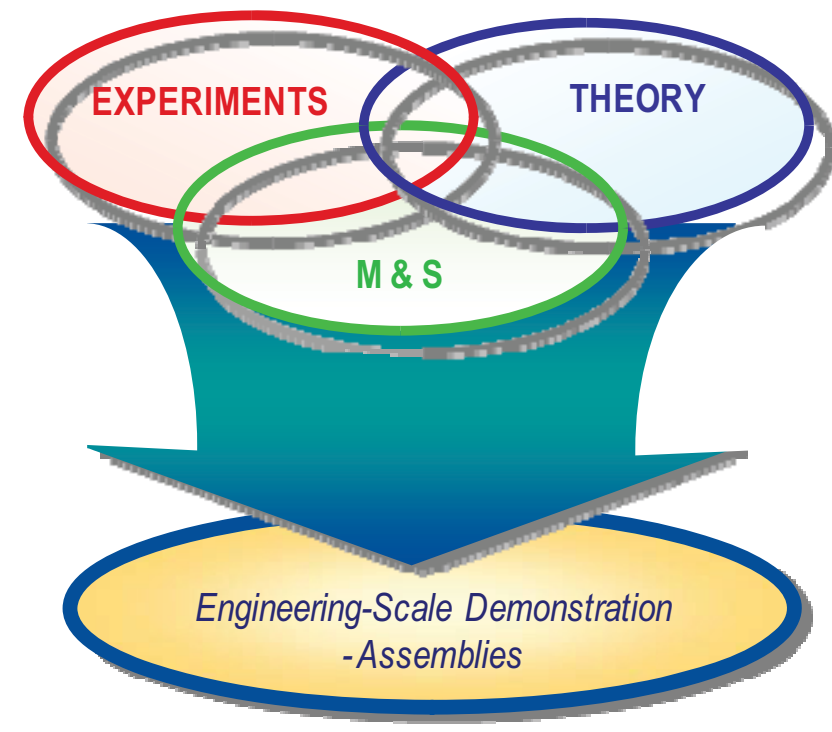

Figure 7. Elements of the "Goal-Oriented ScienceBased Approach" (micron to sub-micron scale characterization) are needed for science-based fuel development. Finally, in situ instrumentation for in pile experiments will be valuable to understand the transient in pile behavior of the fuels and materials.

- Theory - Essential elements of the science-based approach are to build upon existing theories and to develop new theories that explain the various phenomena of interest based either on first principles or observations made during phenomenological testing or uncovered through analysis of modeling results. In the long-term, theory must span from quantum mechanics to continuum mechanics in explaining the behavior of physical systems. A well-integrated approach between experiments and theory development is required for success of the science-based approach. For advanced fuels, the near-term theory development will be a mesoscale (microstructural) understanding of fuels and materials under irradiation conditions.

- Modeling and Simulation - The knowledge and data gained under the experimental and theoretical elements of the science-based approach will be incorporated into an advanced modeling and simulation program that takes advantage of state-of-the-art computing capabilities. Due to the very complex nature of the licensing process for nuclear fuels, a formal science-based approach must be developed and implemented to demonstrate the validity of the newly developed simulation tools for addressing the behavior of fuels and materials in realistic situations and qualify these tools to be used in the licensing process. The technical objective of the modeling and simulation effort is to provide insight into highly non-linear, coupled, multi-physics processes that occur during fuel fabrication and fuel performance. The practical objectives are to:

- Minimize the number of empirical iterations during fabrication and high-dose irradiation testing of fuels by designing the performance into the fuel at the early development phases 
- Reduce the number of prototypes and large-scale experiments needed before demonstration and deployment

- Quantify uncertainties for design and operational parameters.

- Demonstrations - Nuclear energy systems are large-scale, complex facilities characterized by phenomena that can span ten orders of magnitude in space and time. Financing these systems requires the synthesis of complex business considerations and long-term financial commitments. Plant construction requires the use of large amounts of basic commodities such as concrete and steel. Facility operation requires adherence to a plethora of regulations at the local, state, and federal levels. At the same time, the United States regulatory process still relies heavily on experiments to confirm the ultimate safety of nuclear power systems (including the fuels). Ultimately, the amelioration of these risks requires that new nuclear energy systems must be thoroughly demonstrated before commercial deployment. Therefore, new technologies, regulatory frameworks, and business models must be integrated into first-of-a-kind system demonstrations and prototypes. Then construction and operation will provide sufficient top-level validation of system technical and financial performance to enable deployment. For fuels, demonstration means fabrication of test assemblies, typically referred to as lead test assemblies using prototypic processes and tested in a prototypic environment. At the end of testing, it must be demonstrated that the behavior of the LTAs are within the bounds of the established safety and operational envelopes. Historically, the safety-acceptability of advanced fuels in LTAs requires prior transient testing of those fuels.

The typical empirically-based observational approach for fuel development is contrasted with the predictive science-based approach in Figure 8.
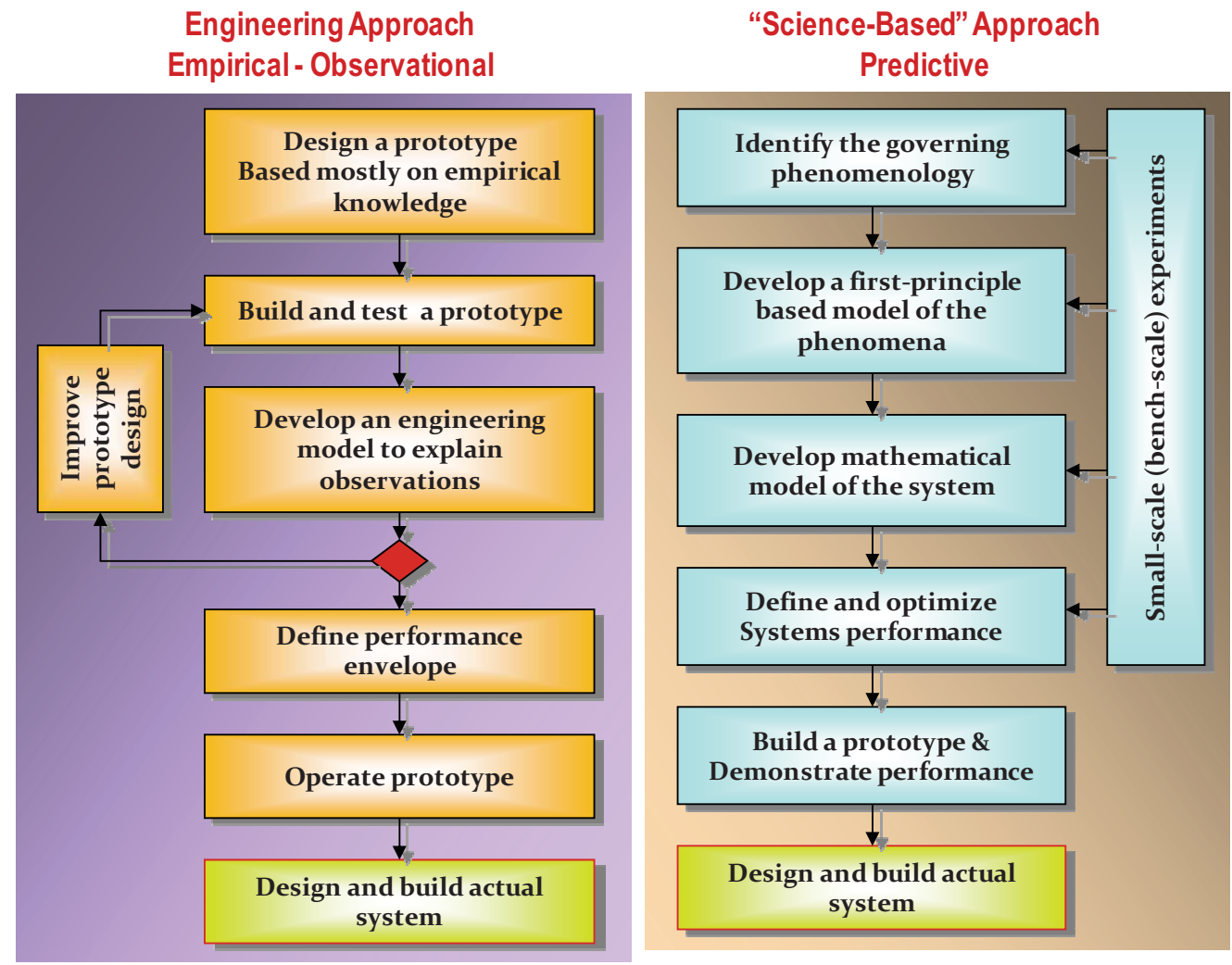

Figure 8. Science-Based Approach versus the Prototype Based Engineering Approach 


\subsubsection{Technology Readiness Levels}

In order to provide a quantitative assessment for the maturity of a given system relative to its full-scale deployment, a technology readiness level (TRL) process was developed and used by the Department of Defense (DOD). Subsequently, NASA also successfully used the TRL process to develop and deploy new systems.

The fuel cycle RD\&D program adopted the TRL concept in order to track the technology maturity of various competing concepts and designs. ${ }^{6}$ To use the TRL as an effective progress-tracking tool, the first step is to create quantitative definitions with specific criteria for different TRLs. The levels range from 1 to 9 , where 1 signifies a new untested and unproven concept and 9 signifies commercial-scale deployment. The TRL level assigned to a technology or its component depends on the performance requirements. For instance, uranium oxide fuels for LWRs are a proven technology and one would bin this technology at TRL 9. However, if a requirement was imposed on the fuel that it need to achieve a burnup in excess of $100 \mathrm{GWd} / \mathrm{tHM}$, this would lower the TRL to 1, provided someone had at least a concept of such a fuel. Many of the grand challenges for advanced fuels development are currently at a TRL 1 or lower (since concepts are still being formed). On the other hand, fuels that can achieve some fraction of the fuel cycle objectives exist at TRL 4 or 5, due to the recent research in the U.S. and abroad. Thus one way of looking at the dual track approach would be to pursue options with TRL 1 in parallel to options that are relatively more mature but with lesser performance expectations at TRL 4 through 6 . The use of TRL's in tracking the performance of the fuel cycle systems, sub-systems, or components provides a quantitative way of measuring progress and comparing different alternatives.

The existing TRL definitions rely heavily on the classical empirical approach used for fuel development. As we move forward, the elements of the science-based approach must be incorporated into the definitions. In the meantime, regardless of how they are achieved, the criteria shown in Table 1 will be used to define the TRLs.

Table 1. Criteria used for the Fuel Development TRL Definitions ${ }^{6}$

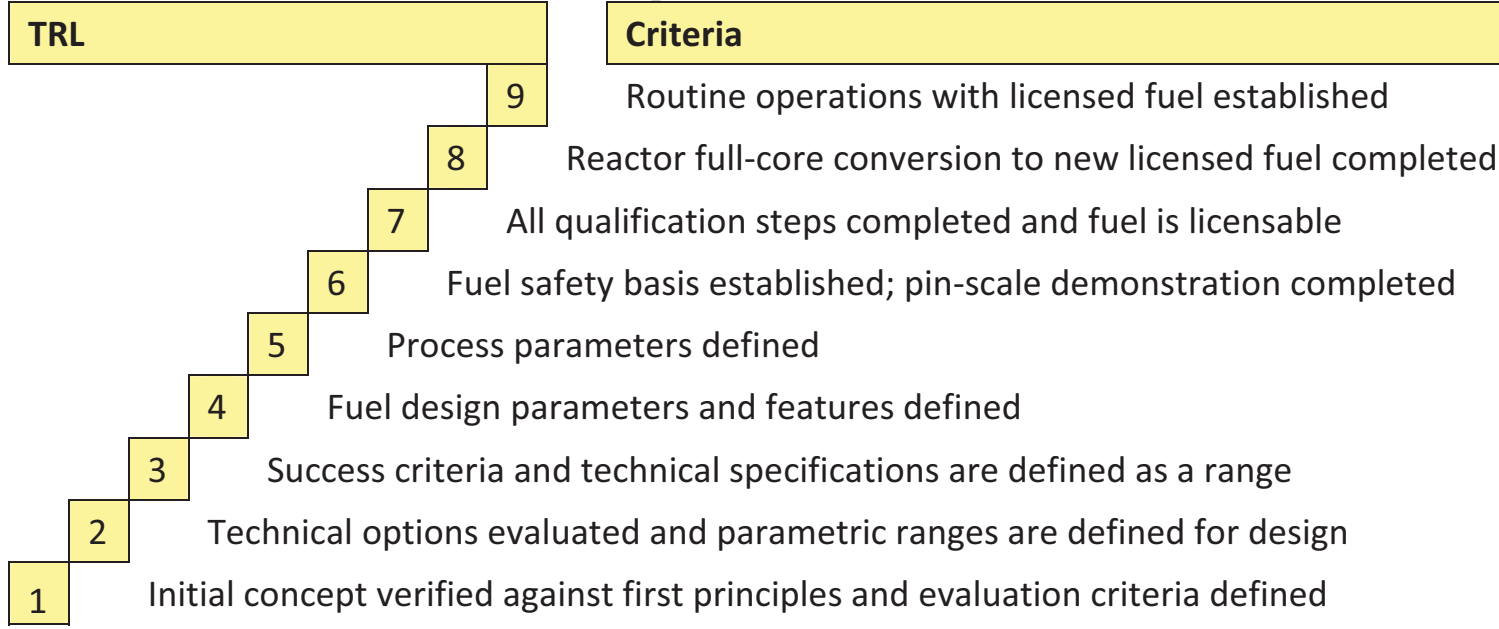

\subsection{RD\&D Areas}

A typical fuel development cycle is shown in Figure 9. The following major research areas are defined based on the cycle. 


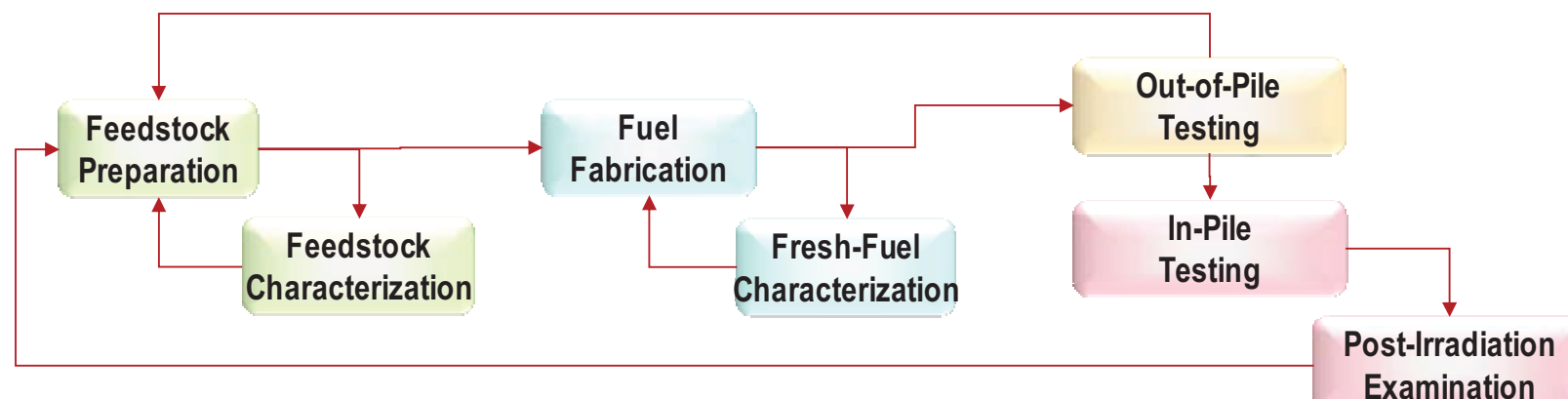

Fuel Fabrication Modeling

Fuel Performance Modeling

Figure 9. Elements of the Fuel Development Cycle

\subsubsection{Analytic Support Activities}

Innovative fuel systems may provide performance improvements allowing such things as greater transmutation efficiency, higher temperature operation, and high reactor energy production, as examples, but require additional research and development over the oxide and metal alloy fuel systems that are being pursued as baseline technologies. These fuel systems are currently at the early research and development stage but warrant investment to support the future nuclear fuel cycles. Innovative fuel designs to achieve higher burnup and higher power density will be pursued in support of the LWR technology. Thorium-based fuels are also included in the innovative fuel design activities. The design activities include fuels (with fertile and inert matrices) and targets with their associated cladding, to support the different fuel cycle options and transmutation strategies.

This program element also includes assessment of in-pile performance of such fuels. The impact of the new fuel/target forms on the normal operations and design-basis accidents that define the operational and safety envelopes of the reactor systems must be established. Fuel failure modes and the impact on the safety envelope also must be established for the proposed innovative fuel forms.

\subsubsection{Fuel Fabrication}

These activities are aimed at the development of advanced fabrication techniques that provide the desired control on fuel microstructure (with inclusion of strategic additives if needed). The early emphasis will be on bench-scale testing of the fabrication processes.

The supply of high purity feedstocks for campaign needs will be identified. Detailed characterization of the feedstock and feedstock conditioning technique development are necessary for advanced fuel development. In later stages of the fuel development, feedstock materials obtained from actual separation processes will be used to validate the predictions about the behavior of the impurities. In addition, development of advanced feedstock characterization techniques are needed to transition to a sciencebased fuel development paradigm.

Theoretical understanding of the effect of the fabrication processes on the fresh fuel microstructure and phase distribution will be pursued. Various techniques such as the Kinetic Monte Carlo (KMC) and Phase Field formulations (and combinations or variations of these techniques) will be used. Numerical process models will be developed to help the fabrication process designers. 
Finally, a mechanistic fuel fabrication plant simulator will be used to guide the fabrication process design at large-scale. The models will first be developed using bench-scale testing and then validated at large scale.

\subsubsection{Characterization of Fuel Samples}

To support the fundamental understanding of the fuel behavior, detailed characterization of the fabricated samples will be performed for properties measurements with emphasis on micro-structural distribution and local properties.

Development of novel characterization techniques to measure properties at micron to submicron scale is essential to support the science-based fuel development program. New techniques will be pursued for fresh and irradiated fuel samples. Radiation hardening of characterization equipment such that it can be used with highly radioactive samples in a shielded environment also is covered under this activity.

For early evaluation and phenomenological understanding of the materials, out-of-pile experiments will be performed using external neutron sources, ion-beam irradiations, or thermal- and/or stress-gradient simulations outside a reactor. Separate effects experiments to support M\&S activities will be designed and initiated.

\subsubsection{Cladding Materials Development}

To meet the grand challenge, innovative cladding materials will be developed to achieve high burnup fuels. This task includes analysis of the micro-structural design options, effect of additives on clad performance, preparation of samples for irradiation, and property measurements. In-pile and out-of-pile testing of the advanced cladding (without fuel) also are covered under this program element, including the post-irradiation examination of the material samples.

The theoretical basis for closure of transport equations will be established concurrently with the irradiation effects at the microstructural level. Theoretical understanding of the phenomena within a single crystal along with the effect of grain boundaries for poly-crystalline systems will be the focus of this task. Various techniques such as the Kinetic Monte Carlo (KMC) and Phase Field formulations (and combinations or variations of these techniques) will be used.

\subsubsection{Irradiation Effects}

These activities include irradiation testing of fabricated fuel samples and cladding materials using ATR and HFIR (including rabbit testing). Joint test design studies will be done for irradiation in international fast reactors. Separate effects experiments to support M\&S activities will be designed and initiated. Later transient testing of selected fuels also will be performed when a transient test reactor is available.

These activities also involve designing an instrumented test capsule for irradiation. For the science-based approach quantification of the irradiation conditions and changes in fuel properties during irradiation is needed to provide the ability to measure fuel conditions during irradiation.

The development of novel in-pile instrumentation to obtain data while the fuel is being irradiated is key to our success for science-based fuel development paradigm. The emphasis would be on instruments that can last a short duration while providing accurate data on the early restructuring behavior and response of the fuel system to steep power and temperature gradients. 


\subsubsection{Post-irradiation Examination}

PIE of irradiated fuel samples (including legacy samples from previous irradiations) is essential in understanding the fuel behavior under irradiation. This includes analysis of the data and comparative evaluation of various fuel types.

Development of novel PIE techniques to measure properties at micron to submicron scale is essential to support the science based fuel development program. New techniques will be pursued for fresh and irradiated fuel samples. Radiation hardening of characterization equipment will be developed for use with highly radioactive samples in a shielded environment.

\subsubsection{Fuel Performance Modeling}

Development of multi-scale fuel performance code based on first principles and with minimal reliance on empirical data at engineering-scale (that is very specific to fuel type and form) will be pursued to support the science-based development of advanced fuels. Verification and validation will be done on the performance code.

\subsubsection{Engineering-Scale Demonstration}

For purposes of fuel fabrication facility, the engineering-scale demonstration means a throughput size which can reliably be scaled up to commercial size in terms of cost, reliability, availability, and maintainability. Detailed scaling analyses are needed as a function of the required processes and equipment but it is expected that the requirement would be the fabrication capability of a few test assemblies per year. For fuel performance, the irradiation of multiple lead test assemblies with predictable outcome in a prototypic environment constitutes engineering-scale demonstration.

\section{RD\&D AREA ACTIVITIES}

Development of any fuel and target form in support of the different fuel cycle categories is within the scope of the Advanced Fuels Campaign, specifically those that are needed to achieve sustainable nuclear fuel cycles. Additional fuel forms that become part of the nuclear energy RD\&D portfolio needed to achieve the other DOE-NE objectives may also be included in the scope if necessary. The major RD\&D areas covered under the scope of the fuel development pathway are as follows:

\subsection{Long Term Timeline}

The overall goal by 2050 is to achieve a complete engineering-scale demonstration of the desired fuel form(s) needed for sustained management of used nuclear fuel by 2050. This assumes a fully-closed fuel cycle using advanced fuel forms containing minor actinides in the form of fuels or targets. Demonstration may be achieved earlier than 2050 by using a fuel cycle option that requires incremental improvements on existing fuel types (e.g., high-burnup LWR fuels). General descriptions of the focus areas during the development phases are provided below.

- 2010 through 2015 - Science-based tools will be developed in terms of theory, experiments, and modeling. The tools will aim at understanding the fabrication and performance processes at the microstructural level and include multi-scale modeling and simulation tools, micron-scale characterization techniques, in situ instrumentation, and phenomenological tests, which are both guided by and inform the theory. The 2015 objective is a framework of predictive models for fuel performance and fabrication using microstructural design of basic systems. 
- 2015 through 2020 - The tools to design advanced fuel forms will be implemented. Theory development, small-scale testing, and modeling and simulations activities continue with a design focus. The 2020 objective is the completion of the microstructural design of innovative fuel forms using the performance and fabrication models. For the LWR fuels pin-scale testing will be initiated.

- 2020 through 2025 - The tools used to design advanced fuel forms will be validated through small-scale integral experiments (both fabrication and performance). The 2025 objective is the completion of model validation and the simulation tools.

- $\quad 2025$ through 2030 - Transmutation fuels and associated fabrication facilities will be designed based primarily on predictive models. Integral experiments will continue to further optimize the design and improve the design tools. The design of the engineering-scale fuel fabrication facility will be completed with a scaling analysis to support subsequent commercial deployment. The 2030 objective is the completion of the designs of fuel assemblies based primarily on predictive models, along with the engineering-scale fuel fabrication facility. LTA testing will be completed for the LWR fuels.

- 2030 through 2035 - Construction of a demonstration facility will be completed, including process definition and a limited number of fuel pins tested in foreign test reactors. The 2035 objective is the completion and operational readiness of a fuel fabrication demonstration facility. Qualification of advanced LWR fuels will be completed.

- 2035 through 2040 - Using the demonstration facility, process testing will be performed for large-scale fuel fabrication of lead test assemblies for insertion into a demonstration transmutation facility (e.g., fast reactor). Selected experiments in foreign test reactors will be completed. The 2040 objective is the completion of lead-test assembly fabrication and qualification for insertion into a demonstration transmuter.

- 2040 through 2050 - Irradiation of lead test assemblies will be completed in a demonstration transmuter and transmutation fuel will be recycled using the demonstration facilities.

\subsection{AFC Strategic Milestones}

AFC Strategic Milestones have been developed to support the three DOE-NE sustainable nuclear fuel cycle options as well as the fuel modeling and simulation activities through 2050. Level 2 and 3 milestones for the first five years $(2010-2015)$ are provided in the next section for the five technical areas of the campaign. All of the activities associated with the milestones support the development of a framework of predictive models and understanding of fuel behavior at a microstructural level. The two overall strategic milestones are

2015: Establish the key experimental and computational elements of the science-based approach for fuel development and complete the transition to science-based development.

2020: Complete all elements of the science-based approach as applied to fuel development and total transformation of fuel development to the new paradigm. Complete the down selection of candidates.

The high-level milestones and decision gateways supporting the nuclear fuel cycle options are as follows:

\section{Fuel Modeling \& Simulation}

2015: Completion of the multi-scale fuel performance modeling platform

2015: Completion of fuel casting and sintering models 
2015: Complete development of a fuel fabrication plant simulator platform

2020: Completion of the multi-scale fuel performance code for design

2020: Fuel fabrication simulator operational

2025: Verification and Validation of the Multi-Scale Fuel Performance Code

Once-Through Fuel Cycle

2015: Down-select advanced LWR fuel concepts for pin-scale testing

2025: Select advanced LWR fuel form/type for Lead Test Assembly (LTA) testing

2030: Initiate the LTA testing

2035: Complete qualification of the advanced LWR fuel (complete LTA testing and PIE)

Modified Open Cycle

2015-2020: Initial selection of fuel forms/types to be developed for MOC

2025: Start fuel fabrication demonstration facility design

2030: Select the fuel form/type for demonstration (LTA testing)

2035: Fuel fabrication demonstration facility operational

2038: Insert LTAs into a prototype reactor/transmuter

2050: Complete LTA testing \& PIE (Fuel Qualification).

\section{Full Recycle}

2015-2020: Initial selection of fuel forms/types to be developed for full recycle option

2025: Start fuel fabrication demonstration facility design

2030: Select the fuel form/type for demonstration (LTA testing)

2035: Fuel fabrication demonstration facility operational

2038: Insert 1st generation TRU-LTAs into a prototype reactor/transmuter

2045: Insert the 2nd generation TRU-LTAs into a prototype reactor/transmuter

2050: Complete LTA testing \& PIE (Fuel Qualification and demonstration of full recycle).

\subsection{AFC Five Year Technical Milestones}

The Advanced Fuels Campaign is divided into the following five technical areas:

- Analytic Support

- Metal Based Fuels Technologies

- Ceramic Based Fuels Technologies

- Coated Particle Fuels Technologies

- Core Materials Technologies

- Irradiation Testing Technologies

The following milestones represent the next five years of fuels RD\&D for the different technical areas under the Advanced Fuels Campaign. It is important to realize that these milestones and deliverables are developed as possible options without any budget constraints. Once detailed budget guidance and an execution plan are approved by DOE, a realistic set of milestones will be developed. 


\subsubsection{Analytic Support Five-Year Scope and Milestones}

The design of the advanced fuel forms that are being considered will be analyzed for further development. Fuel performance will be evaluated in the critical or sub-critical systems of interest along with the impact of the fuels on the safety and operational envelope of the systems. The analytic support team will integrate with the systems analysis activities. The assessments of interest will continue on a yearly basis with continuous documentation. There are no specific milestones for these activities other than annual status reports.

The earliest major milestone is in 2015, where the impact of the advanced LWR fuel forms selected for further development beyond TRL 3 on the LWR operational and safety envelopes will be documented. The analytic support tasks support all three nuclear fuel cycle options including the thorium cycles.

In addition, the Analytic Support team is responsible for the interface with the NEAMS activities. The fuel performance M\&S activities under NEAMS will directly support the science-based approach implemented under the AFC and must be closely coordinated with the experimental activities for successful execution.

\subsubsection{Fuel Performance Modeling Five-Year Scope and Milestones}

The development of a multi-scale fuel performance code based on first principles and with minimal reliance on empirical data at engineering-scale (specific to fuel type and form) will be pursued to support the science-based development of advanced fuels. While experimental activities in support of the performance code are also covered under the AFC, the modeling and simulation will be conducted under the NEAMS program. However, the efforts under NEAMS and the AFC must be closely coordinated. Thus, other than the high level milestones (listed earlier) used to guide the campaign activities, detailed milestones are not included in this plan.

\subsubsection{Metal Based Fuels Technologies Five-Year Scope and Milestones}

The metal based fuels technology development effort is directed towards increasing the understanding of fuel materials (i.e., fuel and cladding) so as to produce a superior quality fuel form from an optimized fabrication system. It is considered that the goal of a high performance fuel design coupled to an efficient fabrication process can be best achieved by integrating experiment with computation at all levels of inquiry (atomic, microstructure or mesoscale, continuum). Fuel performance issues to be addressed include, but are not limited to, fuel constituent redistribution, fuel-cladding-interaction, fission product formation, transport, release, and effect on swelling, microstructure evolution, thermal transport, and mechanical and elastic strain and stress. Fuel fabrication issues to be addressed include, but are not limited to, the need for a simple, robust, and versatile process operable at low cost having adequate throughput and reduced maintenance, the elimination or minimization of losses from elemental volatility and materials interaction, the elimination or minimization of waste, production to specification of a high quality product including elemental, isotopic, and microstructural homogeneity, and proliferation resistance. To achieve this challenging goal, several lines of interdependent and coalescing study must be pursued.

First, the integral testing of evolutionary advanced fuel systems must be complemented with investigation of more innovative fuel concepts that address the fuel performance issues. Likewise, fuel fabrication methods must be developed and optimized to address the number of fabrication issues. Close interplay between the fuel design and the fuel fabrication efforts must be maintained so as to, for example, circumvent institution of a fuel design that creates additional and unconsidered concerns within the fuel fabrication effort. These efforts are cohesively linked via fundamental studies of the fuel materials properties and behavior. To better understand the fuel behavior, theories based on observed phenomena 
must be transposed into computational models for simulation purposes. In some cases, it may be necessary to develop new or alternate theories to explain the observed phenomena. Regardless, a close interaction between experiment and computation is necessary. One of the most challenging issues for this interaction is the construction of one-to-one correspondence between experimentation and computation (i.e., modeling and simulation). This difficulty has a historic foundation in that experimentation has generally been geared towards supporting integral reactor testing with measurements typically at the continuum level (i.e., bulk sample type measurements) on complex multi-component systems whereas computational work is performed on ideal, pure, simple systems at multiple levels (atomic, mesoscale, continuum) but with little interaction between those levels.

Fundamental experimental studies to be performed as complements to the continued studies on established advanced fuel forms can be generally divided into three areas under the guise of separate effects studies: diffusion (mass transport), microstructure evolution, and thermodynamic properties. Here, individual parameters are "isolated" and their influence on behavior quantified. Although conceptually seductive, it must be recognized that virtually all of the fuel behavior phenomena are interrelated and ultimately the interdependence must be quantified through integral or semi-integral studies. It is anticipated that the results from the fundamental studies will strongly aid the interpretation and understanding of the results generated from the more complex systems traditionally investigated.

The fuel properties and behavior separate effects studies on diffusion and mass transport are important to understanding the elemental redistribution that occurs in the fuel during irradiation, including fission product migration and release, as well as fuel-cladding-chemical-interaction (FCCI), which is one of the most critical issues for fuel failure. These studies will follow a path of a sequential increase in the complexity of the systems from isothermal self diffusion to multi component system behavior in a temperature gradient. Each system will be studied under the conditions of no irradiation, ion irradiation, and neutron (i.e., in-pile) irradiation over various time intervals, fluxes, and temperatures. This data is extremely important to the computational effort for validation, initial input, or providing insight for continued development of innovative fuel designs. These studies will require experimental technique development.

The related microstructure evolution studies address specific changes in microstructure with respect to the application of certain stresses and to experimentally map these changes in 3D. In order to be successful, a variety of advanced instrumentation must be employed from state-of-the-art microscopy to application of intense beam sources such as at the DOE Advanced Photon Source (APS) if possible. Efforts will be included to map the microstructure evolution in-situ and real time.

The long acknowledged deficiency in fundamental thermodynamic properties (physical and mechanical) of the actinides and actinide bearing materials will be addressed through a systematic investigation of relevant actinide bearing systems. These include the elements ( $\mathrm{U}, \mathrm{Pu}, \mathrm{Np}, \mathrm{Am})$, binaries (NpZr, $\mathrm{AmZr}$, PuAm, etc.), ternaries (UPuZr, UPuAm, UPuNp, etc), quarternaries (UPuAmZr, UPuNpZr, etc.), and quintaries (UPuNpAmZr, UPuNpAmMo, etc.). Data such as free energies of formation relevant to phase diagram calculation, heat capacities, thermal expansion, and thermal diffusivity for thermal conductivity determination, bulk and Young's moduli, elastic tensors, etc. will be determined. If possible, low temperature (i.e., below room temperature) data will be generated that is important for validating atomic level calculations.

In order to provide the highest quality data, the systematic fundamental studies will require very high purity materials not readily available at the present time. As such, a continuous effort to produce high purity materials must be undertaken. In conjunction with this, the ability to quantify the purity of the materials must be established through development and implementation of exacting trace element analysis techniques as well as the capability and techniques for handling such materials that will avoid possibilities 
of cross contamination or detrimental chemical reaction. To this end, very small sample handling may be necessary.

Finally, progress from the studies outlined above towards the goal of increased understanding to produce a high performance fuel design coupled to an efficient fabrication process will require the development and adaptation of advanced instrumentation to the study of radioactive and highly radioactive materials. In addition to bulk type (i.e., continuum level) measurements, efforts to perform measurements at ever increasing spatial resolution and temporal range must be integrated into the program. It is exactly these types of measurements that will allow the one-to-one correspondence between experiment and computation.

Metal fuels fabrication and characterization tasks primarily support the modified-open (M) and full recycle (F) options. However, an initial feasibility study for once-through metallic fuel for LWRs will also be conducted in support of the open fuel cycle option. The milestones are provided in Figure 10. The scope includes:

- Feedstock preparation and characterization with emphasis on high-purity and well-characterized feedstock for the science-samples.

- Advanced fabrication process development and testing along with fabrication of science-samples (including single crystal samples).

- Detailed characterization of the science-samples with emphasis on fuel properties, behavior, and microstructural characterization.

- Advanced characterization techniques with emphasis on micron and sub-micron scale characterization.

- Documentation of a primary fabrication process.

- Fuel fabrication modeling and simulator development. 


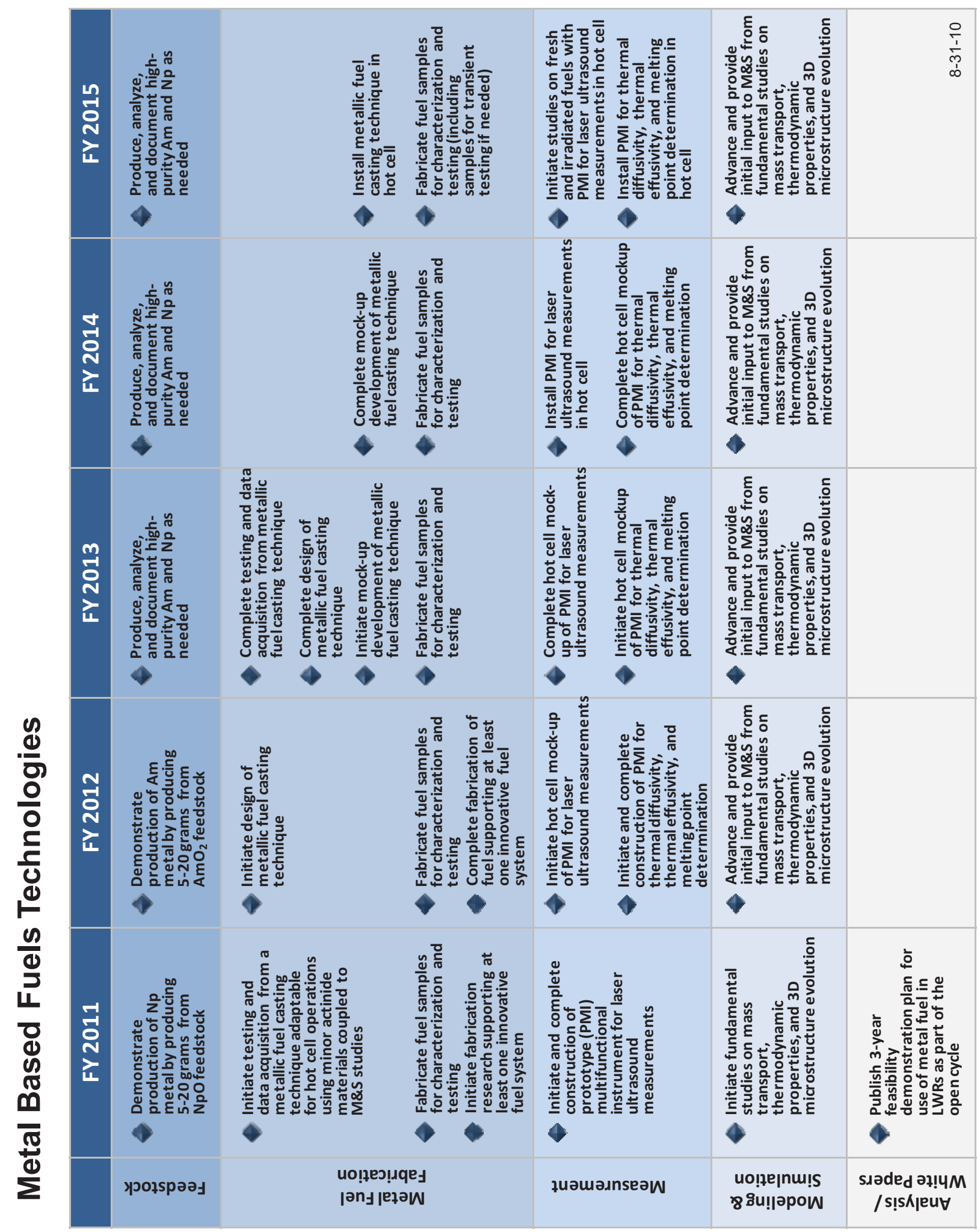

Figure 10. Metal Based Fuels Technologies 5-Year Milestones 


\subsubsection{Ceramic Based Fuels Technologies Five-Year Scope and Milestones}

Ceramic fuel development for the five-year horizon is designed to be a balance of effort that seeks transformational R\&D while incrementally advancing fuel technology. This balance is established via fundamental fuel material processing and performance studies that advance our fundamental understanding of the relationships for given fuel forms between fuel composition, pellet fabrication processing, corresponding material properties and subsequent fuel performance.

The ceramic fuel fabrication and characterization tasks support all three fuel cycle options $(\mathrm{O}, \mathrm{M}, \mathrm{F})$ including the thorium cycles. The open fuel cycle is supported via technology that seeks to improve conventional fuel performance (e.g., higher power, deeper burn), the modified open cycle via fuel types suited to increased performance and decreased waste generation with minimal reprocessing, and the closed fuel cycle via technology enabling incorporation of minor actinides for advanced ceramic-based fuels/targets. Improvements in fabrication technology (e.g., low loss, net shape, and advanced techniques) and fuel performance are pursued.

The balance of effort includes fuel fabrication and performance studies which encompass both separate effects-type testing and integral effect-type testing. The separate effects test studies are designed to establish and articulate the underlying physical processes at the lower length scales while supporting definition of phenomenology at the meso-scale and subsequent understanding of behavior at the engineering (continuum) scale. In addition to the resulting improvement of theoretical understanding of fuel fabrication and performance, the separate effects testing aspect of the program is intended to directly inform and support the development of predictive fabrication and performance models.

The integral effects aspect of the fuel performance testing program most directly supports incremental advancements in fuel technology, but, by coordinating design of such testing with the separate effects testing, the integral effects studies are used to validate and benchmark those tests. Due to the generally longer timeline for the integral effects tests, these tests are run in parallel with the separate effects tests but the resulting performance data lags the separate effects data and so for the validation aspect these tests primarily serve to confirm the additive nature of the separate effects tests.

The five year milestones support improved fundamental understanding of fuel fabrication and performance, but due to the limited nature of existing technology to support a modern fuel development campaign, the milestones also by necessity include development and implementation of key characterization and testing technology, e.g., spatially and temporally resolved techniques for composition, temperature and property measurements.

The fuel testing plan includes both in-pile and out-of-pile testing with coupled separate effects and integral effects tests. The ceramic fuels efforts are primarily focused on oxides but include conventional LWR fuels, fast reactor fuels, transmutation fuels and targets, and innovative fuel concepts. Compositions are based upon urania, and conventional urania-plutonia mixed oxide fuels but advances fuel types such as ceramic-ceramic composite (inert matrix or dispersion fuels) and thoria-based fuels are also included at the initial developmental stages. The plan includes tests designed to establish understanding of fundamental relations via studies of effects of advanced processing techniques on subsequent fuel performance, articulation of the role of minor actinides and similar minor constituents/phases on performance, and studies of advanced fuel types relative to baseline urania or MOX fuels, all of which support establishment of fundamental relations between chemistry, processing, fabricated structure, fuel properties and fuel performance for the different fuel types.

The milestones are provided in Figure 11. The scope includes:

- Feedstock preparation and characterization with emphasis for the science-samples on high-purity and well-characterized feedstock. 
- Advanced fabrication process development (pellets, vibro-pac, sphere-pac) and testing along with fabrication of science-samples (including single crystal samples).

- Detailed characterization of the science-samples with emphasis on establishing the relations between processing, microstructure/chemistry, properties and in-pile performance.

- Advanced characterization techniques with emphasis on micron and sub-micron scale characterization.

- Fuel fabrication modeling and simulator development. 


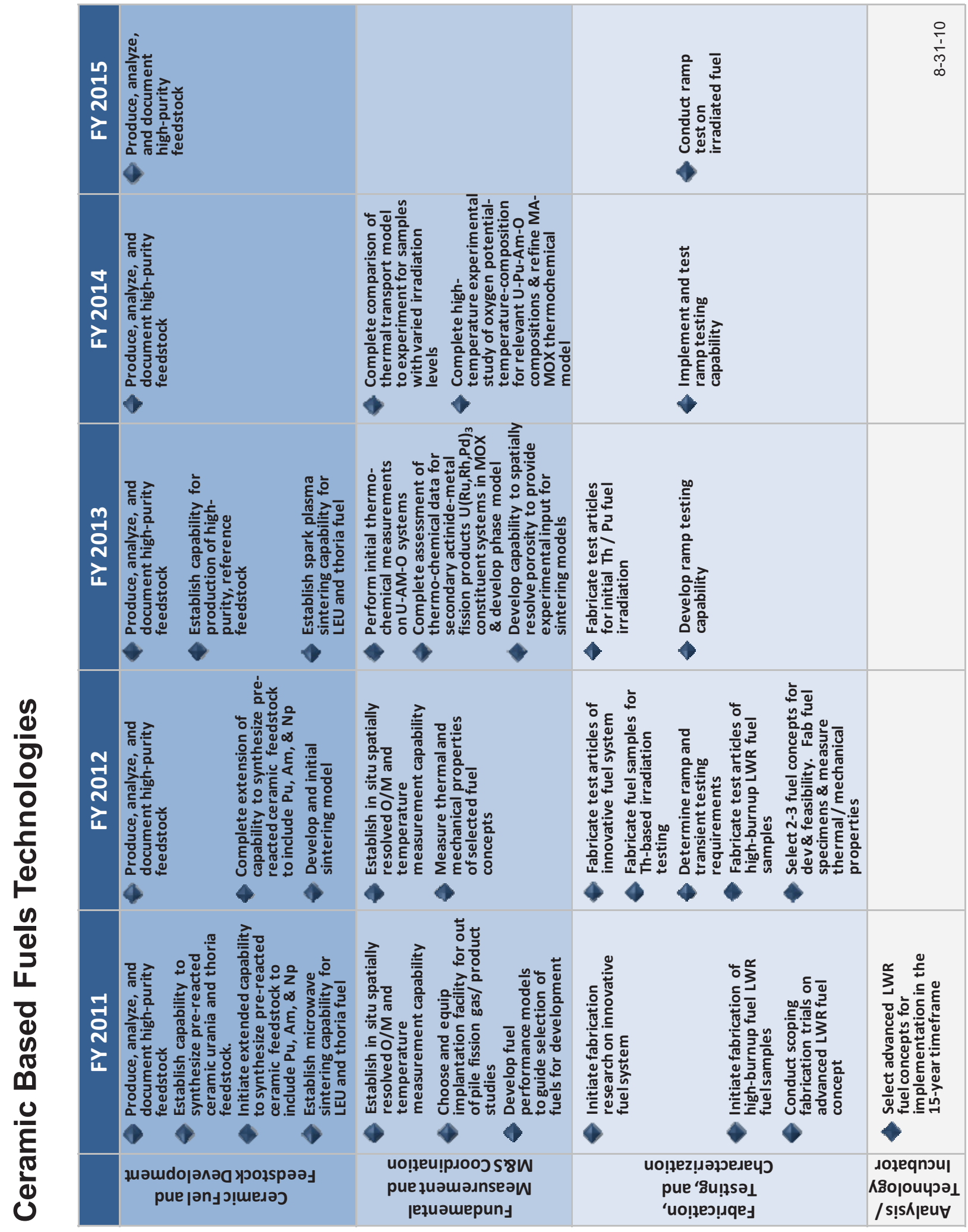

Figure 11. Ceramic Based Fuels Technologies 5-Year Scope and Milestones 


\subsubsection{Coated Particle Fuels Technologies Five-Year Scope and Milestones}

Coated particle fabrication and characterization tasks primarily support the modified-open (M) fuel cycle option. However, an initial feasibility study for once-through coated particle fuel for LWRs will also be conducted in support of the open fuel cycle option. The milestones are provided in Figure 12. The scope includes:

- Preparation and characterization of feedstock with emphasis on high-purity and wellcharacterized feedstock for the science-samples.

- Advanced fabrication process development (including coating) and testing along with fabrication of science-samples.

- Detailed characterization of the science-samples with emphasis on microstructural characterization.

- Advanced characterization techniques with emphasis on micron and sub-micron scale characterization.

- Fuel fabrication modeling and fabrication facility simulator.

- Initial irradiation performance verification. 


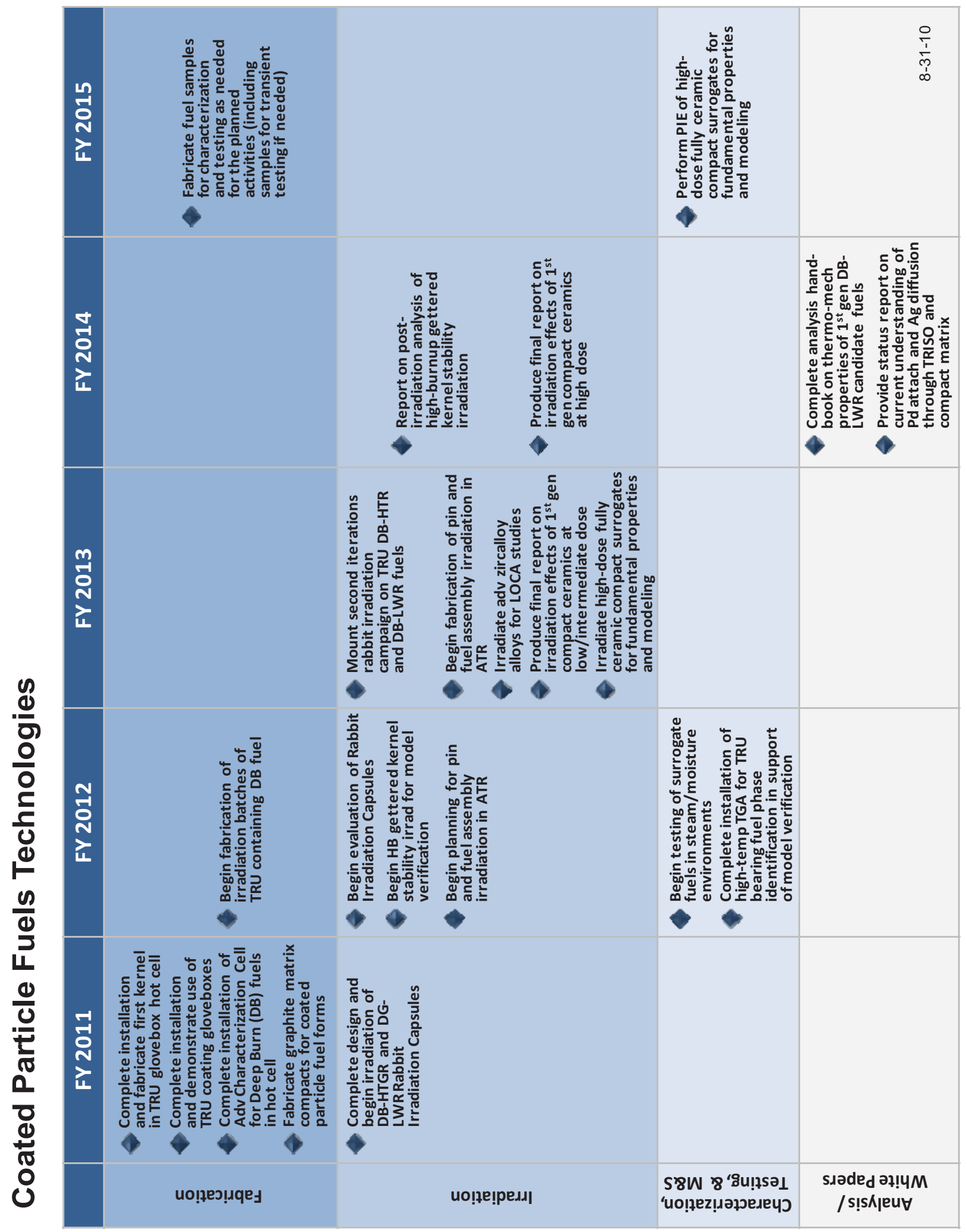

Figure 12. Coated Particle Fuels Technologies 5-Year Scope and Milestones 


\subsubsection{Core Materials Technologies Five-Year Scope and Milestones}

The core materials technology development tasks support all three fuel cycle options (O, M, F) including the thorium cycles. For these fuel cycle options the goal of maximizing uranium utilization while reducing nuclear waste is accomplished through irradiating the nuclear fuels to very high burnup (up to or greater than $40 \%$ ) in a high neutron flux. In order to develop fuels to accomplish this grand challenge, core materials (cladding and ducts) must be fabricated and tested to be able to withstand this challenging environment of radiation effects to displacement doses greater than 400 dpa that promote low temperature embrittlement, radiation induced segregation, high temperature helium embrittlement, swelling and accelerated creep; corrosion with the coolant, and chemical interaction with the fuel (FCCI) while maintaining the ability to be welded and processed into engineering forms (e.g., clad tubing, hexagonal ducts). The milestones are provided in Figure 13. The scope includes:

- Developing a knowledge base of the mechanical properties and microstructural changes in HT-9 after irradiation to doses up to $200 \mathrm{dpa}$. This data is critical to determining the radiation dose limits of this engineering material while the detailed microstructural measurements down to the atomistic scale provide critical information for developing advanced models to understand and predict radiation effects in these materials.

- Developing advanced materials with improved radiation tolerance to $400 \mathrm{dpa}$ or greater. This is being explored through evolutionary improvements of advanced alloys such as ferritic/martensitic steels or oxide dispersion strengthened steels while at the same time exploring revolutionary improvements through innovative new materials. This research includes developing new materials and performing irradiation testing on these materials through long term reactor and short term ion irradiations.

- Developing advanced materials for adding coatings or liners to the inside of cladding tubes to resist fuel clad chemical interactions. This task includes developing manufacturing techniques for fabricate coated or lined tubes while also investigating innovative nanoscale coatings with improved radiation tolerance.

Through achieving these milestones on time, we expect by 2015 to develop and test advanced clad materials for fast reactors to $300 \mathrm{dpa}$ and develop liners to prevent FCCI to $>30 \%$ burnup in ATR. This data, which will be collected in an FCRD materials handbook, will aid in the development of advanced models. 


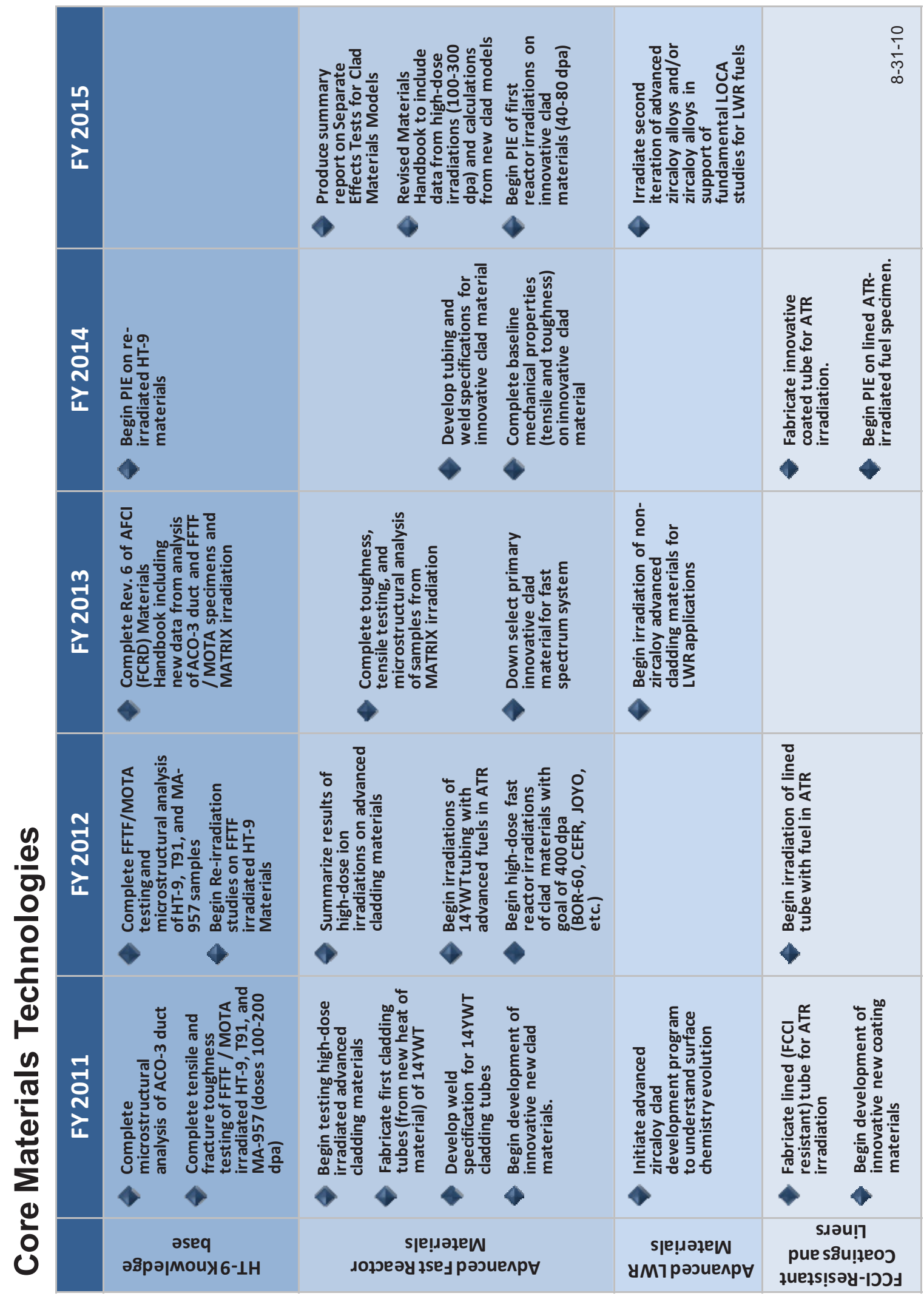

Figure 13. Core Materials Technologies 5-Year Scope and Milestones 


\subsubsection{Irradiation and Testing Five-Year Scope and Milestones}

The Five Year Irradiation Schedule is provided in Figure 14. The irradiation testing and postirradiation examination tasks support all three fuel cycle options $(\mathrm{O}, \mathrm{M}, \mathrm{F})$ including the thorium cycles. The primary objectives of the tasks to be pursued during the upcoming five years fall into three areas of emphasis.

The first area of emphasis is the feasibility testing of emergent, innovative fuel concepts that have the potential to make substantial progress toward achieving the Advanced Fuels Grand Challenges. Tasks in this area will largely consist of small-scale, integral experiments performed in the ATR coupled with conventional postirradiation examinations. Fast reactor fuel concepts that prove feasible and promising during this testing phase will be candidates for irradiation testing in fast reactors abroad, assuming such testing space can be negotiated.

The second area of emphasis is the development of a capability to perform separate effects testing (SET), both in-pile and out-of-pile, to broadly advance the theoretical understanding of nuclear fuel behavior under irradiation and to inform/validate the complementary advanced modeling and simulation effort. Tasks in this area will consist of designing and deploying new irradiation testing capabilities, including low-dose hydraulic rabbit tests in HFIR and an irradiation test vehicle capable of controlling temperature as well as making in situ measurements of fuel performance parameters in the ATR. Coupled with the new irradiation testing capabilities will be the implementation of advanced postirradiation examination capabilities to characterize irradiated fuels at the micro- and/or nano-scales.

The third area of emphasis is to gain an understanding of the differences and/or limitations between testing advanced fast reactor fuels in neutron-shrouded positions in thermal test reactors in contrast to their performance in a prototypic fast-spectrum environment. Tasks in this area will consist of both analytical assessments as well as comparisons between equivalent fuels irradiated in both thermal and fast-spectrum reactors. These results will be important input to guiding the irradiation testing direction of current and future fuel development programs.

The major milestones developed to advance the three areas of emphasis include:

\section{FY-2011:}

- Initiate low-dose metallic fuel testing in HFIR hydraulic rabbit

- Begin irradiation of first innovative fuel concept in ATR (fast reactor application)

- Identify key technologies to pursue for in situ measurements of fuel performance phenomena

- Initiate PIE on legacy EBR-II/FFTF fuels to inform thermal-fast comparison

- Complete planning for transportation of FUTURIX-FTA from France to INL

\section{FY-2012:}

- Initiate low-dose ceramic fuel testing in HFIR hydraulic rabbit

- Begin irradiation of second innovative fuel concept in ATR (thermal reactor application)

- Complete design of ATR irradiation test vehicle for SET testing (AFC-4)

- Issue preliminary report on PIE of low-dose metallic fuels from HFIR

- Ship FUTURIX-FTA to INL and initiate PIE

\section{FY-2013:}

- Initiate fuels SET testing using AFC-4 irradiation test vehicle

- Demonstrate application of in-pile instrumentation to measure fuel performance phenomena in situ 
- PIE on FUTURIX-FTA complete

- Issue preliminary report on PIE of low-dose ceramic fuels from HFIR

- Issue preliminary report on results of micro- and/or nano-scale characterization techniques for irradiated nuclear fuels

FY-2014:

- Issue preliminary report on use of micro- and/or nano-scale characterization data to validate advanced M\&S activities

- Issue preliminary report on PIE of AFC-4 SET testing

- Issue Comparison Report on ATR vs. FUTURIX-FTA fuels

- Issue Comparison Report on ATR vs. EBR-II/FFTF fuels

FY-2015:

- Define new fast reactor irradiation experiments for promising innovative fuel concepts

- Deploy new PIE capabilities to conduct micro-scale characterization of irradiated fuels

- Issue Assessment Report on testing of fast reactor fuels in thermal test reactors 


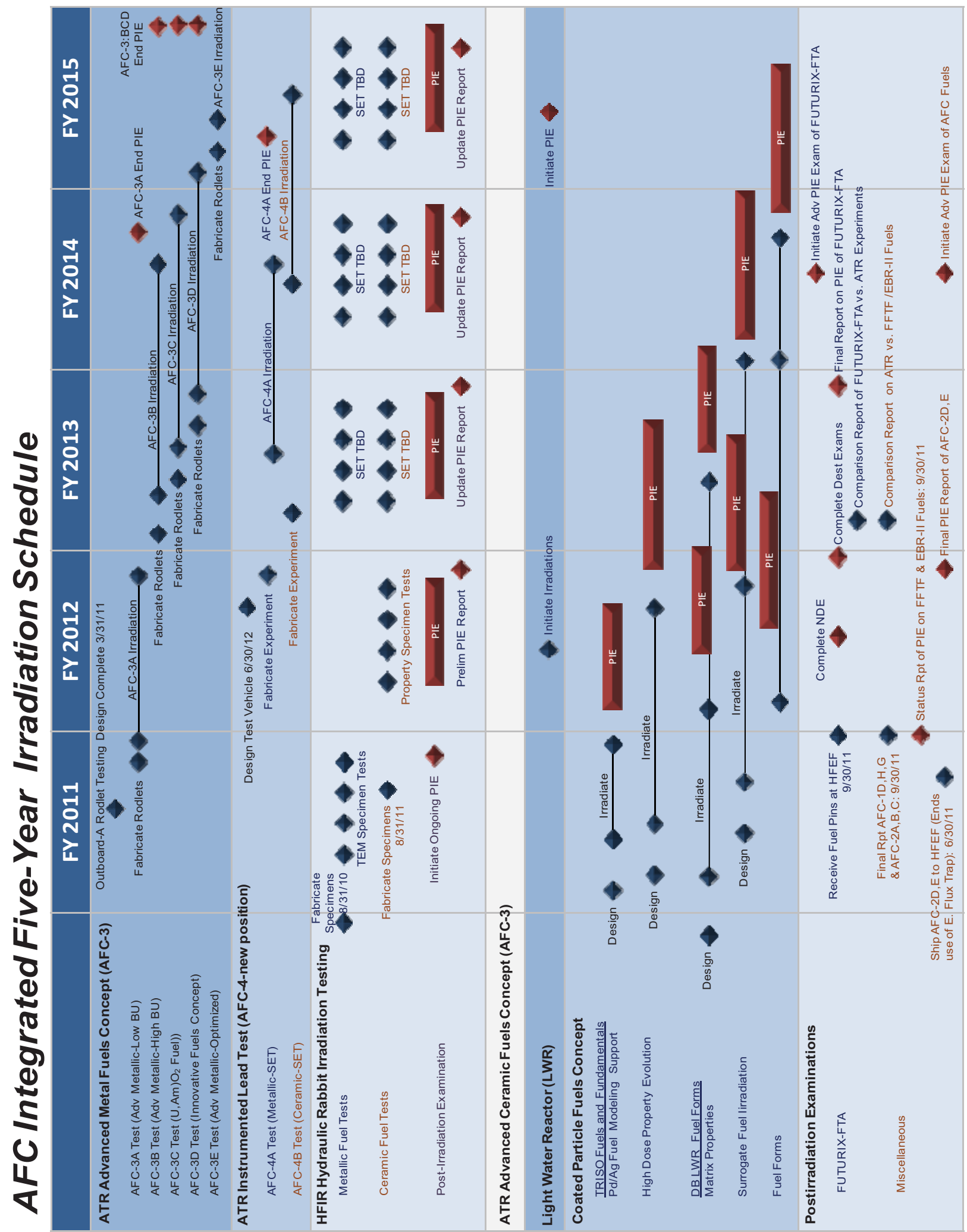

Figure 14. Irradiation and Testing 5-Year Scope and Milestones 


\section{INFRASTRUCTURE NEEDS}

The FCRD Advanced Fuels Campaign utilizes the RD\&D infrastructure across the Department of Energy National Laboratory complex as well as in the U.S. University system. University facilities are used for low hazard and unirradiated R\&D activities and the National Laboratory infrastructure is used for handling highly radioactive materials and conducting high hazard activities. Activities involving major infrastructure in the National Laboratory system are primarily located at the Idaho National Laboratory, Los Alamos National Laboratory, Oak Ridge National Laboratory, and Pacific Northwest National Laboratory. The U.S. national infrastructure needed to support nuclear fuel research and development is aging and generally in need of significant maintenance, upgrade, and repair. The current use of this infrastructure is described below in addition to identification of the needed infrastructure to support future (out-year) efforts in Advanced Fuels RD\&D.

The deficiencies in the RD\&D infrastructure are a major challenge for AFC. In many cases, the facilities needed to support the necessary activities do not exist and are expensive to obtain (e.g., fast test reactor for fast-spectrum fuels and transient testing capability). As a result of multiple decades of neglect, some facilities need considerable refurbishment and upgrades to accomplish the nuclear energy research. In addition, state-of-the art equipment must be available (designed, procured, installed) to support the science-based approach to fuel development. Technologies developed in other areas outside nuclear energy (e.g., advanced measurement techniques, advanced simulation capabilities) must be imported and adopted into nuclear energy RD\&D. Thus, considerable investment is needed in the coming decade to prepare the nuclear infrastructure for high levels of research. Subsequently, new larger-scale facilities will be needed to achieve the demonstration objectives.

\subsection{Fabrication Infrastructure}

The development of advanced nuclear fuels is conducted at four different scales: bench scale, laboratory scale, engineering scale, and prototypic scale. The next five years of development will primarily focus on development activities at the bench and laboratory scale. These activities will be conducted with surrogate and representative radioactive materials depending upon the development level of the nuclear fuel system of interest. The Advanced Fuel program will be conducting fabrication development activities on multiple fuel systems including traditional and innovative fabrication processes. Because fabrication activities involve fissile and accountable materials, these activities need to be conducted in the Fuel Manufacturing Facility at the INL and the PF-4 facility at the LANL. Generally, they are conducted in biologically shielded gloveboxes and containment systems. Non-radioactive material fabrication development activities are conducted in the laboratory and university facilities.

Over the next five years, fabrication infrastructure will be needed to develop the capabilities needed to perform research and development on new fabrication processes as well as improving existing fabrication systems.

\subsection{Characterization Infrastructure}

Characterization of nuclear fuels is performed at all stages of the fuel development process and requires infrastructure that can handle both irradiated and unirradiated materials. The development of material property and fuel performance correlations must be conducted.

\subsubsection{Pre-Irradiation (un-irradiated materials)}

Characterization and material property measurements are required on fresh fabrication and unirradiated fuel materials to establish baseline design calculations and beginning-of-life condition. Characterization of unirradiated fuel materials will be conducted to evaluate the effectiveness of fabrication process R\&D. 
This type of characterization requires finer resolution to support elucidation of the phase structure behavior and needs equipment capable of handling fissile and radioactive minor actinide bearing materials. Higher resolution results are difficult to obtain in the existing aging infrastructure. Update, refurbishment, and maintenance of existing equipment is needed.

\subsubsection{Post-Irradiation (irradiated materials)}

Combined with the Nuclear Energy Advanced Modeling and Simulation Campaign (NEAMS), the longterm goal of AFC is to improve the ability to predict fuel performance and to significantly shorten the time required for fuels qualification through the use of predictive science. This requires not only the development of multi-scale simulation models, but also the validation of the models with pertinent data. Only then will researchers achieve the fundamental understanding of fuel fabrication and performance necessary to perform virtual experiments and avoid a time consuming Edisonian development approach. This goal is ambitious and requires the use of available instruments in radiation environments for which they were not originally designed. Another part of the solution involves establishment of new PIE capabilities that are unique to this type of research.

\subsection{Irradiation and Testing Infrastructure}

Developing an understanding of the microstructural behavior of nuclear fuels and materials requires significant irradiation and testing infrastructure. Traditionally, development of nuclear fuels has been accomplished using an integral testing approach; test, characterize, modify, and test again. Fuel development using a goal-oriented scientific approach requires testing capabilities in addition to those that provide prototypic irradiation environments. The facilities needed to support this approach include many of the neutron, proton, ion, and spallation irradiation facilities existing in the DOE complex. These facilities will be used by the fuel development program and where needed, foreign facilities and infrastructure will be pursued under international agreements. Eventually a prototypic neutron irradiation environment will be needed.

In terms of reactor irradiation, the Advanced Test Reactor (ATR) and High-Flux Isotope Reactor (HFIR) will be used to irradiate fuel and material samples. Testing that requires a prototypic fast spectrum irradiation will be conducted in foreign test reactors through International collaborations. Eventually, a fast spectrum irradiation capability and re-establishment of transient testing capability will be needed to support the advanced fuel development program.

\section{AFC ORGANIZATION}

The AFC Management Team, shown in Figure 15, consists of the Federal Technical Manager, National Technical Director, Deputy National Technical Directors, Campaign Coordinator, Quality Assurance Lead, Technical Leads, Program Leads, and Work Package Managers. The roles and responsibilities for each are summarized below. 


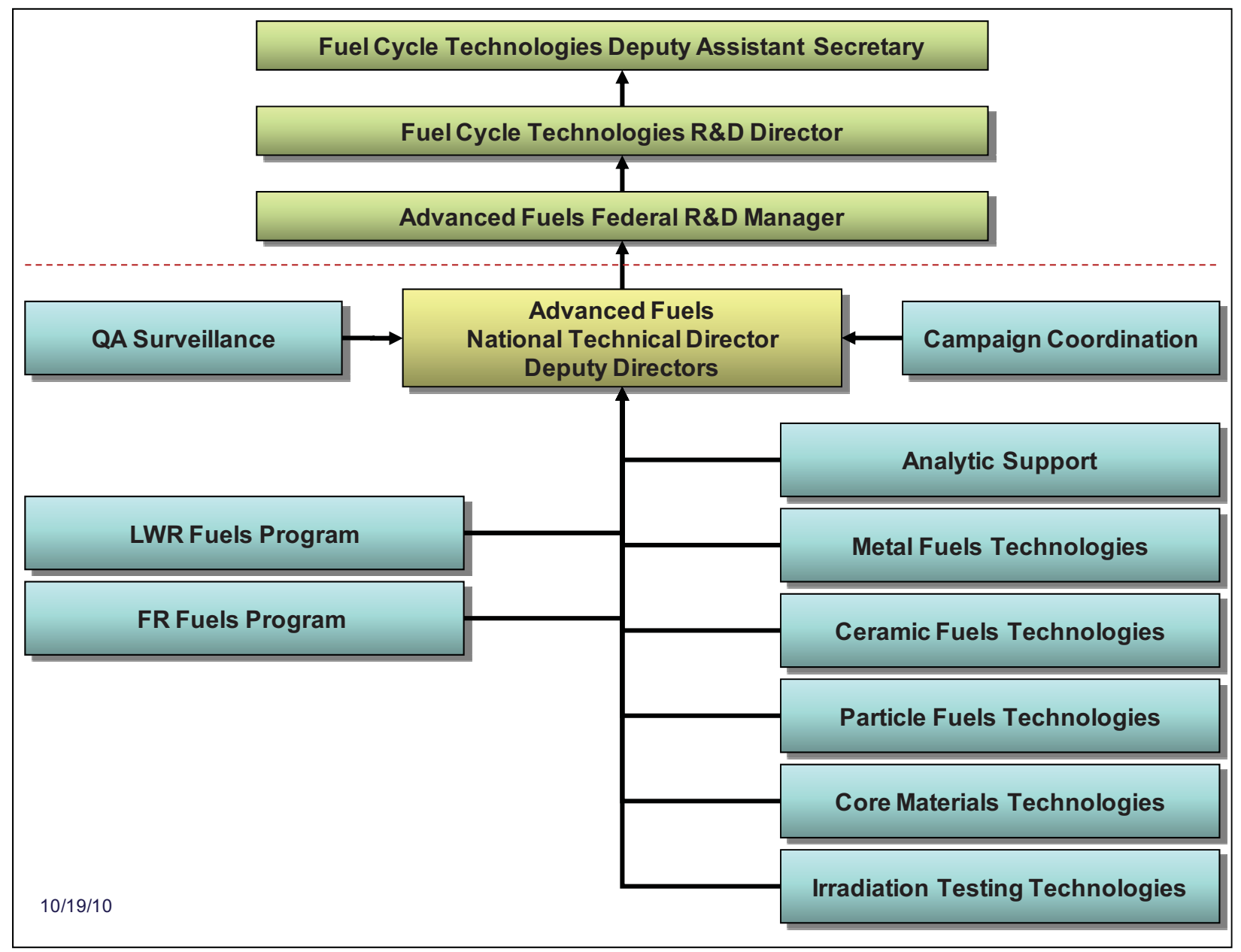

Figure 15. AFC Management Structure

\subsection{Advanced Fuels National Technical Director}

The following are the primary roles and responsibilities of the Advanced Fuels National Technical Director

- Report to the Federal Technical Manager for the Advanced Fuels under FCRD Director.

- Define and execute the advanced fuel development plan following the DOE guidance.

- Provide technical leadership for the national fuels development program.

- Participate in FCRD strategic planning and provide technical recommendations when requested by DOE.

- Assist DOE in developing and implementing international collaboration agreements pertinent to the AFC.

- Participate in and/or co-chair (on behalf of DOE) international working groups related to fuel development.

- Participate in periodic NTD meetings, including weekly teleconferences.

- Participate in internal and external review meetings. 
- Assist DOE in performing technical and programmatic reviews of University programs.

- Coordinate with NRC and industry.

- Represent FCRD in relevant national and international working groups, workshops, meetings, and conferences (provide technical presentations with DOE's concurrence).

- Chair the Advanced Fuels Campaign Quarterly Review meetings.

- Review and approve progress reports (monthly and quarterly) and technical reports generated by the campaign participants.

- Ensure the Fuel Cycle Technologies Quality Assurance Program Document requirements are implemented for all applicable AFC activities.

\subsection{Advanced Fuels Deputy National Technical Director}

While the AFC NTD's main focus is to perform the interface functions external to the campaign, the deputy directors are primarily responsible for day-to-day management of the AFC.

The primary roles and responsibilities of the deputy NTDs are to:

- Assist the AFC Director (as needed) with the following tasks:

- $\quad$ Run the weekly/monthly teleconference meetings with the AFC Team.

- Review and approve monthly and quarterly status reports.

- Review and approve monthly financial and schedule status data.

- Approve work packages and baseline change requests on behalf of the AFC NTD (as needed).

- Represent the AFC Director in workshops, meetings, working groups, and conferences as requested.

- Organize and conduct yearly workshops with universities and/or researchers working in the fuel development area.

- Assume responsibilities as the point-of-contact when the NTD is not available.

\subsection{Campaign Coordinator}

The primary roles and responsibilities of the Campaign Coordinator are to ensure that the following functions in support of AFC management and integration are performed:

- Develop the functional and technical requirements for the AFC based on input from the technical leads and the fuel design analysis.

- Organize and run the AFC Quarterly meetings and publish the meeting summary.

- Compile and submit the monthly status reports from the technical leads.

- Organize, manage, and document AFC related technical meetings to support decision analysis, strategic planning, and lessons learned exercises.

- Compile and submit the AFC year-end Accomplishment Reports.

- Develop and maintain the high-level campaign documents.

- Develop and maintain AFC schedules. 


\subsection{Technical Leads}

AFC Technical Leads are assigned to manage national DOE Complex-wide teams focused on technology development in the following areas:

- Analytic Support

- Metal Based Fuels Technologies

- Ceramic Based Fuels Technologies

- Coated Particle Fuels Technologies

- Core Materials Technologies

- Irradiation Testing Technologies

The primary roles and responsibilities of the Technical Leads include:

- Provide technical coordination of workscope definition and implementation on tasks related to the technical areas.

- Participate in AFC Quarterly Review meetings.

- Develop the input for the Advanced Fuels Multi-Year Implementation and Execution Plans.

- Participate in the development of the Functions and Requirements Document (F\&RD) document.

- Assist the NTD in preparing yearly planning packages and work-packages.

- Participate in internal and external review meetings and present status of technology development activities as needed.

- Assist the NTD in reviewing the technical reports pertinent to technology development activities.

- Assist the NTD in reviewing university proposals pertinent to technology development activities.

- Assist the NTD in developing and implementing international collaboration tasks pertinent to technology development and participate in relevant international working group meetings when needed.

- Coordinate with NRC and industry.

- Ensure that AFC work activities are performed in accordance with the FCT QAPD requirements.

- Ensure that procedures and processes are developed and/or followed as necessary to meet the FCT QAPD requirements regardless of the performer or location of work.

- Ensure Quality Assurance requirements are flowed down to subcontractors, vendors or others performing FCT funded work.

- Assist the NTD in other tasks as needed.

- The technical lead for the analytic support activities also is responsible for interfacing with the NEAMS activities

- Define the M\&S needs for the campaign and communicate them to the appropriate NEAMS teams

- Understand the experimental activities needed by the NEAMS teams and incorporate them into the campaign activities by working with other TL's 
- Incorporate the tools developed by the NEAMS teams into the campaign activities and provide feedback to the NEAMS teams on the performance of the tools.

\subsection{Program Leads}

Program Leads (PL) primarily serve as the liaison with the Reactor Campaigns within the DOE-NE programs. Currently two program leads are identified to interface and coordinate the activities with the Light Water Reactor Sustainability (LWRS program) and The Fast Reactor Technology Development Program:

- Coordinate the AFC activities with the relevant reactor program and assist the program managers in their fuel development activities.

- Define the technical plans and activities to support the relevant reactor programs.

- Coordinate with the TLs to develop planning packages and work packages supporting the relevant programs.

- Develop the input for the Advanced Fuels Multi-Year Implementation and Execution Plans.

- Participate in internal and external review meetings and present status of technology development activities as needed.

- Assist the NTD in various coordination tasks as needed, such as reviewing technical reports and university proposals pertinent to technology development activities.

- Assist the NTD in developing and implementing international collaboration tasks pertinent to technology development and participate in relevant international working group meetings when needed.

\subsection{Work-Package Managers}

The Work-Package (WP) managers are responsible to execute the tasks defined within the WPs. The following are the specific responsibilities of the WP managers:

- Supervise the work defined. within the WP to ensure that the work is progressing within budget and on schedule

- Provide monthly input to the project control system (PCS) relative to the status of the WP tasks.

- Notify the TLs responsible for the WP when schedule or budget problems develop (in addition to monthly project control updates) and assist the technical lead and NTD to develop corrective actions.

- Prepare baseline change proposals (BCPs) for technical lead and NTD approval when needed.

- Provide input to monthly and quarterly reports on the status of WP tasks.

- Attend internal and external review meetings (as requested).

- Follow the FCT QAPD requirements for Work Package Managers

- Work with the AFC QA Lead to ensure that PI's are aware of specific QA requirements for the work packages and that objective evidence is maintained or performance of those requirements.

\subsection{Quality Assurance Lead}

- Coordinate the QA efforts across the AFC. 
- Provide assistance and support to the work package manager in determining Quality Rigor Level(s) and review the Quality Rigor Level determinations prior to work package finalization.

- Provide QA support to the work package managers in determining the QA procedures and policies necessary to properly implement their scope of work and assist with estimating resources for QA support across all work packages to address related QAPD requirements.

- Assist Work Package Managers and technical staff to effectively implement the QAPD requirements.

- Plan, schedule, and perform or ensure performance of surveillance and assessment activities of AFC related work activities.

- Attend Campaign meetings as needed to assist with QA implementation and provide QA Program updates or report on issues or successes with the QA Program.

- Provide feedback to NTD concerning AFC QA performance issues.

- Assist NTD in verifying university work under contract with the National Laboratories are performing work in accordance with the FCT QAPD requirements and that quality assurance records are being maintained.

\section{FUNDING NEEDS}

The milestones presented in this document are predicated on some preliminary budget assumptions. At this point there is considerable uncertainty with respect to the 5-year budget. However, to put the milestones in perspective, an initial budget distribution chart was developed based on $\$ 40$ to $\$ 45 \mathrm{M}$ per year funding for the next 5 years.

Clearly, as the guidance is clarified, the Advanced Fuels Federal Technical Manager and the National Technical Director will update the budget distributions. At that point, the milestones may have to be revised if the actual budgets are considerably different than the planning basis for the 5 -year duration. This will be done on a yearly basis during the revisions to this execution plan.

\section{SUMMARY AND CONCLUSIONS}

The Advanced Fuels Campaign has been given responsibility to develop advanced fuel technologies for the DOE using a science-based approach focusing on developing a microstructural understanding of nuclear fuels and materials. The science-based approach will combine theory, experiments, and multiscale modeling and simulation aimed at a fundamental understanding of the fuel fabrication processes and fuel and clad performance under irradiation. The design of fuels and cladding will require predictive capabilities to achieve the desired performance (in contrast to more empirical observation-based approach traditionally used in fuel development).

The dual-path of the Advanced Fuels Campaign optimizes RD\&D to serve two purposes. First, use evolutionary advances on current knowledge to develop the fuels needed to define and demonstrate advanced reactor and fuel cycle options with sufficient certainty that program milestones and budgets can be reasonably anticipated and planned. Second, explore and discover new innovative, revolutionary fuels that can fundamentally improve our ability to directly support the development of sustainable nuclear fuel cycles as part of the DOE-NE Roadmap Objective 3. 


\section{REFERENCES}

1. Nuclear Energy Research and Development Roadmap, Report to Congress, U.S. DOE Office of Nuclear Energy, April 2010.

2. “R\&D Objective 1 Implementation Plan,” DRAFT DOE Report (TBD).

3. “R\&D Objective 2 Implementation Plan,” DRAFT DOE Report (TBD).

4. “R\&D Objective 3 Implementation Plan,” DRAFT DOE Report (TBD).

5. “R\&D Objective 4 Implementation Plan,” DRAFT DOE Report (TBD).

6. Carmack, W. J., and Pasamehmetoglu, K.O., Definition of Technology Readiness Levels for Transmutation Fuel Development, FCRD-FUEL-FUEL-TD-RT-2008-000051, Rev. 0, January 2008. 